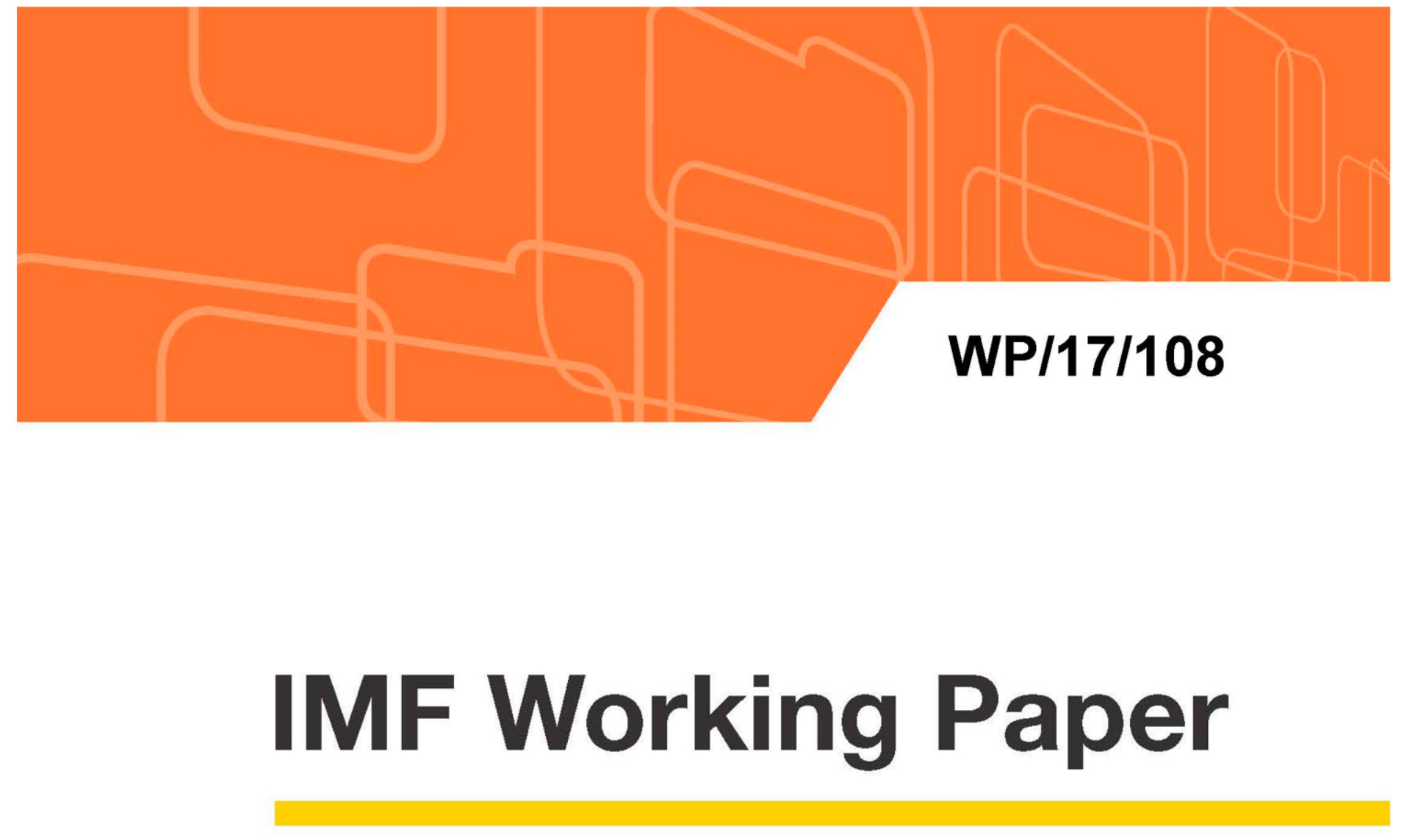

\title{
Lasso Regressions and Forecasting Models in Applied Stress Testing
}

\author{
Jorge A. Chan-Lau
}

IMF Working Papers describe research in progress by the author(s) and are published to elicit comments and to encourage debate. The views expressed in IMF Working Papers are those of the author(s) and do not necessarily represent the views of the IMF, its Executive Board, or IMF management. 


\title{
WP/17/108
}

\section{IMF Working Paper}

\section{Lasso Regressions and Forecasting Models in Applied Stress Testing}

\author{
Jorge A. Chan-Lau
}

IMF Working Papers describe research in progress by the author(s) and are published to elicit comments and to encourage debate. The views expressed in IMF Working Papers are those of the author(s) and do not necessarily represent the views of the IMF, its Executive Board, or IMF management.

$$
\text { I N T E R N A T I O N A L M O N E T A R Y F U N D }
$$




\title{
IMF Working Paper
}

Institute for Capacity and Development

\section{Lasso Regressions and Forecasting Models in Applied Stress Testing Prepared by Jorge A. Chan-Lau \\ Authorized for distribution by Ralph Chami}

May 2017

\section{IMF Working Papers describe research in progress by the author(s) and are published to elicit comments and to encourage debate. The views expressed in IMF Working Papers are those of the author(s) and do not necessarily represent the views of the IMF, its Executive Board, or IMF management.}

\begin{abstract}
Model selection and forecasting in stress tests can be facilitated using machine learning techniques. These techniques have proved robust in other fields for dealing with the curse of dimensionality, a situation often encountered in applied stress testing. Lasso regressions, in particular, are well suited for building forecasting models when the number of potential covariates is large, and the number of observations is small or roughly equal to the number of covariates. This paper presents a conceptual overview of lasso regressions, explains how they fit in applied stress tests, describes its advantages over other model selection methods, and illustrates their application by constructing forecasting models of sectoral probabilities of default in an advanced emerging market economy.
\end{abstract}

JEL Classification Numbers: C1, C53, G21

Keywords: Stress test, forecasting, machine learning, model selection, lasso, relaxed lasso Author's E-Mail Address: jchanlau@imf.org 


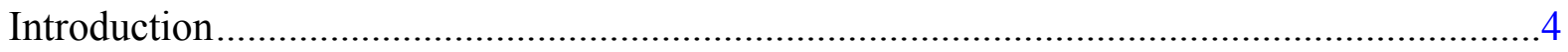

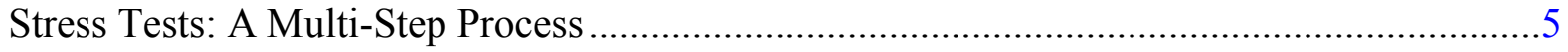

Model Selection Challenges in Stress Tests ................................................................6

Machine Learning: The Interpretability-Flexibility Tradeoff..........................................

Linear Models: Subset Selection and Shrinkage Methods .............................................

Lasso Applications in Finance, Economics, and Financial Networks ...............................12

A Stress Test Application: Forecasting Probabilities of Default ........................................14

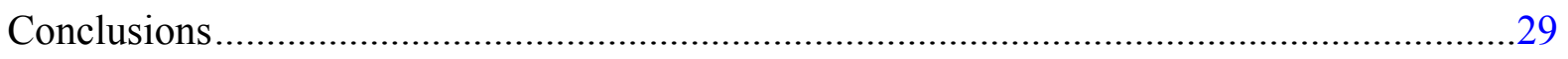

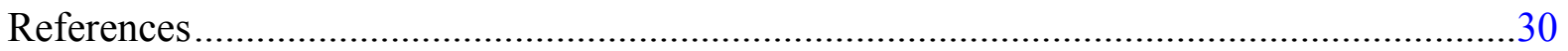

\section{Figures}

1. Geometry of Least Squares, Ridge Regression and Lasso regression ............................11

2. Lasso and relaxed Lasso, mean squared errors ......................................................... 16

\section{Tables}

1. Lasso and relaxed lasso, coefficient estimates, $\lambda$-min specification ................................19

2. Lasso and relaxed lasso, coefficient estimates, $\lambda$-1se specification................................ 24 


\section{INTRODUCTION ${ }^{1}$}

Owing to the large costs associated with bank failures and financial crises, as experienced in the global recession of 2008-9, it has become important to assess the vulnerability of financial institutions to severe economic and financial shocks. Among quantitative tools, stress tests are widely used to examine risks to financial institutions and financial stability more broadly (Bookstaber et al, 2013). Stress tests are also important policy tools when supported by credible official backstops, raising confidence on the ability of policy makers to manage well the risks envisaged in stress scenarios (Orphanides, 2015). ${ }^{2}$

Recent work on stress testing has been mainly oriented towards scenario design. One strand of the literature has focused on the generation of severe, plausible, and coherent stress scenarios consistent with historical crisis episodes and potential regime changes. ${ }^{3}$ On the policy front, there have been efforts for integrating stress tests into financial sector surveillance and oversight with a view towards enhancing regulatory and supervisory guidance (IMF, 2012; Bookstaber et al, 2013).

Improving forecasting models, however, has been somewhat neglected in recent applied stress test work. This is not a minor omission, since the numerical outcome of the forecasting models influence policy recommendations as well as business strategies. As stress scenarios become more comprehensive, encompassing an increasing number of primary variables, model selection and forecasting become challenging even within the family of linear models.

This paper argues that model selection and forecasting in stress tests can be facilitated using techniques borrowed from the field of machine learning. These techniques have not been widely used in econometric and financial applications despite their robustness and good performance in other fields where large datasets are typical. Notable exceptions in applying them in stress tests and default prediction are Kapinos and Mitnik (2015), and Perdeiy (2009). The former suggest using the least absolute shrinkage selection operator (Lasso) to link bank performance indicators to macroeconomic variables. The latter uses Lasso regressions to predict bankruptcy using non-traditional financial indicators as covariates. This paper extends their work by delving in more depth on the conceptual issues justifying the use of machine learning techniques, and discussing them more extensively. ${ }^{4}$

\footnotetext{
${ }^{1}$ The author thanks Oliver Chen, Dimitri Demekas, Elisabeth Van Laere, Li Lin, seminar participants at the South African Reserve Bank for helpful comments. This paper has benefitted from an extensive empirical study on model selection methods conducted by Zhangran Guan, Qian Luo, Gangxuan Wang, and Baoxin Wu under the author's supervision.

${ }^{2}$ Notwithstanding the increased importance of stress tests in policy formulation, there are some valid concerns about their limitations (Borio et al, 2012).

${ }^{3}$ Yuen (2013) and Zandi (2013) provide a concise overview on stress scenario design. Breuer et al (1999), Flood and Korenko (2013), and Glasserman et al (2015) propose advanced analytical approaches.

${ }^{4}$ Machine learning has made some inroads in financial engineering. See Gyorfi, Ottucsak, and Walk (2012). Lasso regression, which is explained later, and its many variations are increasingly being used in forecasting
} 
The organization of the rest of the paper is as follows. Section II provides an overview of the multi-step process in a standard stress test. Within this context, section III how the large number of primary variables included in a stress scenario leads to a curse of dimensionality problem and complicates the model selection process. Section IV argues machine learning techniques are preferable than other dimension reduction techniques in addressing the curse of dimensionality. Section V discusses subset selection and shrinkage methods, including Lasso. After the presentation of the conceptual underpinnings of Lasso estimation, Section VI describes Lasso applications in the areas of finance, economics, and financial networks. Section VII illustrates the use of Lasso estimation in forecasting probabilities of default in an advanced emerging market economy. Section VIII concludes.

\section{Stress Tests: A Multi-Step Process}

A standard stress test comprises several steps. The first step is stress scenarios design. This involves choosing the length (or horizon) of the scenarios, selecting the primary variables to stress, and specifying their paths under each scenario. The number of primary variables can be quite large as is the case in supervisory stress scenarios specified by supervisory authorities.

For instance, the U.S. Federal Reserve included sixteen domestic economic and financial variables, and twelve international variables in the scenarios specified in the 2015 Comprehensive Capital Analysis and Review (CCAR) of U.S. banks. The Bank of England specified more than sixty primary variables for its 2015 annual stress test exercise (Bank of England, 2015). Finally, the European Banking Association (EBA), in its stress tests of banks in the European Union (EU), included government bond yields, equity prices, house price shocks, and the impact of funding shocks on real GDP growth for twenty-seven EU countries. It also included changes in real GDP growth for twenty countries and regions outside the EU (European Systemic Risk Board, 2014).

In the second step, performance indicators for the firms included in the stress test are forecasted using econometric and statistical models, a.k.a. satellite models. The primary variables are included in the models as covariates or explanatory variables. As an illustration, in the case of a bank forecasting models identify the dynamics of non-performing loans (NPLs) and provisions related to its loan portfolio under the stress scenarios. The choice of metrics to evaluate the performance of a firm depends on the goal of the stress test. In solvency stress tests, for example, the relevant metrics are those associated with the default risk of the firm such as capital adequacy ratios in the case of banks, and statutory capital and technical provisions ratios in the case of insurers. ${ }^{5}$

multivariate macroeconomic time series, factor identification and covariance matrix estimation in finance, and the construction of financial networks, as reviewed in Section III.

${ }^{5}$ Different perspectives on forecasting models applied to stress testing are reviewed in Rosch and Scheule (2008), Siddique and Hasan (2013), and Zhang (2013). On linking forecasting models to performance metrics, see Chan-Lau (2015) among others. 
The final step comprises an evaluation of the weaknesses and strengths of individual firms, and an overall assessment of system-wide vulnerabilities based on the performance indicators. The evaluation then serves to guide business strategy if conducted by the firm itself as part of its risk management process, or policy measures if conducted by supervisory authorities. For example, the U.S. Federal Reserve uses the results of the stress tests conducted under the CCAR exercise to grant or deny approval of the capital distribution plans of the banks. Banks that fail the stress tests are required to resubmit revised plans ensuring their capital buffers would be sufficient to withstand the shocks envisaged in the stress scenario.

\section{Model Selection Challenges in Stress Tests}

The large number of primary variables specified in stress scenarios poses a challenge for the design, selection, and estimation of forecasting models. In the case of the CCAR, restricting models to use only contemporaneous values of the variables and ruling out interactions lead to $2^{28}$ possible linear models for explaining a single dependent variable, say, the default rate of a specific asset class. Model selection intractability worsens as the number of potential models grows linearly with the number of variables to forecast.

Moreover, in the context of macro stress tests, the dimensionality of the data may exceed the length of the sample size raising concerns about model overfitting. In these tests, data is typically available at an annual frequency and may be available only for few years. In this case, least squares cannot yield unique coefficient estimates and some method is necessary to reduce the number of covariates included in the model.

Given the large set of potential covariates, multicollinearity is likely to pose problems. This situation justifies selecting a reduced subset of variables for forecasting purposes. Arguably, expert judgment could help to identify the covariates relevant for the forecasting exercise facilitating the model selection process. However, in the context of a relatively complex firm, e.g. a commercial bank, expert judgment may not compensate for the lack of specialized and detailed knowledge on the firm's operations and exposures, including on its main counterparties. Expert judgment, especially if exercised by outsiders to the firm, may create blind spots and foster an unjustified sense of security.

Dimension reduction techniques offer a formal approach for dealing with the curse of dimensionality. Commonly used techniques are factor analysis and principal component analysis, which construct factors and components as linear combinations of the covariates. Typically, only a reduced number of factors and components are sufficient to explain the variability of the data. For instance, three principal components are enough to explain the term structure of government yield curves. While useful, there is an important caveat with dimension reduction techniques: it is somewhat difficult to associate an economic meaning to a factor or a principal component. Hence, it may be difficult to specify the path of a factor under a given scenario or understand what a negative shock to the factor is.

Expert judgment and dimension reduction techniques lead to lower number of potential covariates ahead of the model selection stage. This may not be desirable from an economic perspective. Financial and nonfinancial corporations are becoming increasingly global, and 
domestic and international factors affect their operations, profitability, and solvency. Reducing the number of covariates prior to selecting the forecasting model may not reveal what the drivers of a firm's performance are. Arguably, it may be preferable to address the curse of dimensionality at the model selection level rather than at the covariate level. Machine learning methods excel in this task. ${ }^{6}$

\section{MACHINE LEARNING: THE INTERPRETABILITY- FLEXIBILITY TRADEOFF}

Machine learning encompasses a number of techniques for identifying patterns and relationships in the data, making it suitable for forecasting and simplifying the model selection process. ${ }^{7}$ In the realm of machine learning, forecasting models falls under the category of supevised learning, in which we are interested in finding a rule, e.g. an econometric model, that maps the set of covariates or inputs, into an output, e.g. the ratio of non-performing loans in an asset category. Linear regression models are just one subset of supervised learning models, and are not discussed here since they are already familiar to economists and analysts involved in stress tests and are thoroughly covered in introductory and advanced econometric textbooks such as Greene (2011) and Woodbridge (2012).

Different machine learning methods are available for forecasting, with increased flexibility offset by increased difficulty to interpret the results. More flexible methods are better at capturing patterns in the data but simpler, easier to interpret methods are better suited for understanding and communicating results. Among the methods, in decreasing order of interpretability, we have subset selection, lasso regressions, least squares, generalized additive models, trees, support vector machines, and methods combining different base learning methods such as bagging and boosting.

The bias-variance tradeoff formalizes the tension between interpretability and flexibility. Given a forecast method or learning algorithm, its expected mean squared error (MSE) can be decomposed into its squared bias, i.e. errors due to erroneous assumptions underlying the method; its variance, i.e. errors due to the sensitivity of the method to noise in the calibrating data set; and the variance of the residual term. The more flexible the method the lower its bias since it can approximate better the true relationship existent in the data. But increased flexibility increases the variance of the method since it attempts to fit not only true data points but also the unavoidable noise present in the data set.

Since stress tests are an input for formulating business strategy or guiding policy, the tests' results and conclusions need to be communicated to different constituencies, including senior decision makers, each with a different grasp and understanding of the technical details underlying the assumptions and analytical methods. This situation places a premium on interpretability rather than flexibility since it is somewhat difficult to build persuasive

\footnotetext{
${ }^{6}$ An alternative approach to selecting sparse models is to use aggregate forecasts of multiple models (Claeskens and Hjort, 2008). An extensive exploratory analysis suggests this may not be feasible in high dimensional problems (Guan, Luo, Wang, and Wu, 2014).

${ }^{7}$ Or in machine learning parlance, forecasting can be referred to as predictive analytics or predictive modeling. For a thorough introduction to machine learning methods, see James et al (2013) or Mohri et al (2012).
} 
arguments based on black-box analysis. Whenever possible, hence, linear models are preferred. By using non-linear transformation of the covariates, these models could also capture some non-linearity in the data.

\section{Linear Models: Subset Selection And Shrinkage Methods ${ }^{8}$}

Among linear models, linear regression is the most widely used method among economists and financial analysts. In a linear regression, the mean of the independent variable conditional on the covariates is an affine function of the covariates. Note, however, that linear models could exhibit low bias and high variance. In linear regressions, the fit can be improved by including a large number of covariates. Including all potential covariates minimizes the bias of the model at the expense of higher variance. As a result, the predictive power of the model and its interpretability are negatively affected.

In response, a number of methods can help reduce the number of covariates in linear regression models. The methods fall into two different categories: subset selection methods and shrinkage methods. The next sections describe the different model categories, and put forward arguments for singling out Lasso regression, a shrinkage method, as the preferred choice for stress test purposes.

\section{A. Subset selection methods}

Subset selection methods aim at finding the optimal number of covariates in a linear regression, and include two categories, best subset selection and stepwise selection. The latter are further classified into forward stepwise and backward stepwise selection methods. ${ }^{9}$ In the case of $p$ possible covariates, including perhaps interacting variables and lagged values of the variables, best subset selection searches for the best combination of covariates among the set $2^{p}$ of all possible linear combinations. An optimality criterion applied to the fit of the model vis-à-vis observed data determines what model is best. Typical criteria include the Akaike Information Criterion (AIC), the Bayesian Information Criterion (BIC), and the adjusted $R^{2}$. Since the algorithm must search over all of the $2^{p}$ potential models, best subset selection performs well only if the number of variables, $p$, is small. In practice, efficient algorithms work well with as many as 30 to 40 variables. ${ }^{10}$

Forward stepwise selection starts with a least squares model with no covariates, adding one variable at a time based on its contribution to improving the model fit, typically as measured by the residual sum of squares (RSS) or highest $R^{2}$. Starting with a model including only the constant term, the first covariate selected for inclusion is the one generating the higher RSS among all models in the one covariate family. After the selection of the first covariate, the

\footnotetext{
${ }^{8}$ See, among others, Hastie et al (2008), James et al (2013), and Hastie et al (2015) for a detailed discussion of the topics covered in sections B and C.

${ }^{9}$ See Miller (2002) and James et al (2013) for details.

${ }^{10}$ Miller (2002) and James et al (2013).
} 
method generates the family of models with two covariates that includes the first covariate. Within this family, the method selects the model with the higher RSS, which yields the second covariate. The process continues until obtaining a model with $p$ covariates. Of the $p$ models generated, each with $k$ covariates, $k=1, \ldots, p$, the final model selected is the one maximizing an optimality criterion, e.g. AIC, BIC, or adjusted $R^{2} .^{11}$

Backward stepwise selection starts with a least squares model including all covariates, with each subsequent model with one less variable until only one variable is left. The variable selected for deletion is the one that contributes the least to the explanatory power of the model. At the end of the backward elimination process, there is be a set of $p$ models, each corresponding to the best performing model in the family of models with one covariate, two covariates, and so on.

As in the case of forward stepwise selection, the final model is the one that performs the best among the set of best performing models according to the chosen optimality criterion. Contrary to forward stepwise selection, it is not possible to apply backward stepwise selection when the number of observations is less than the number of covariates. If the matrix of covariates is full rank, or with rank at least equal to the number of observations, the RSS of the linear regression will be zero.

Computational costs in stepwise selection are lower than in best subset selection since the number of models evaluated is only $1+p(p+1) / 2$ instead of $2^{p}$. While computational savings are substantial, there is no guarantee that stepwise selection may yield the same solution as the best subset selection method. The set of $n$ variables that yields the smallest RSS in a linear regression with $n$ covariates does not necessarily contain the same subset of $n-1$ variables yielding the smallest RSS in a linear regression with $n-1$ covariates. Thus, forward and backward stepwise selection may not need to converge to the same model nor to the model chosen by the best subset selection method. All of these methods, however, could generate reasonable forecasting models that do not need to incorporate all $p$ covariates.

\section{B. Shrinkage methods and Lasso Regression}

Shrinkage methods aim to reduce (or shrink) the values of the coefficients to zero compared with ordinary least squares. The advantage of shrinkage methods is that the estimated models exhibit less variance than least squares estimates. In addition, some shrinkage methods also reduce the number of covariates included in the regression model by yielding coefficient estimates exactly zero, facilitating the model selection process.

Two widely used shrinkage methods are ridge regression (Hoerl, 1962) and the Lasso (Least Absolute Shrinkage Selection Operator) regression (Tibshirani, 1996). Their similarities and differences, as well as those relative to least squares estimation, are apparent by examining the optimization problems solved by each method:

\footnotetext{
11 The forward stepwise selection can be viewed as a simplified case of the least angle regression (LARS) (Hastie et al, 2015).
} 

(1) Least Squares:
$\min _{\beta_{0}, \beta_{j}} \sum_{i=1}^{n}\left(y_{i}-\beta_{0}-\sum_{i=1}^{p} \beta_{j} x_{i j}\right)^{2}$,
(2) Ridge Regression:
$\min _{\beta_{0}, \beta_{j}} \sum_{i=1}^{n}\left(y_{i}-\beta_{0}-\sum_{i=1}^{p} \beta_{j} x_{i j}\right)^{2}$ subject to $\|\beta\|_{2} \leq t$,
(3) Lasso Regression:

$$
\min _{\beta_{0}, \beta_{j}} \sum_{i=1}^{n}\left(y_{i}-\beta_{0}-\sum_{i=1}^{p} \beta_{j} x_{i j}\right)^{2} \text { subject to }\|\beta\|_{1} \leq t \text {, }
$$

where $y$ is the vector of observations of the independent variable, $x$ denotes the covariates, $\beta$ are the corresponding coefficients, \|\|$_{1}$ and \|\|$_{2}$ are the $L_{1}$ and $L_{2}$ norms respectively, and $t$ is a user-specified parameter. The Lagrangian formulation of the ridge and Lasso regression are respectively:

$$
\begin{array}{ll}
\text { Ridge Regression: } & \min _{\beta_{0}, \beta_{j}} \sum_{i=1}^{n}\left(y_{i}-\beta_{0}-\sum_{i=1}^{p} \beta_{j} x_{i j}\right)^{2}+\lambda\|\beta\|_{2}, \\
\text { Lasso Regression: } & \min _{\beta_{0}, \beta_{j}} \sum_{i=1}^{n}\left(y_{i}-\beta_{0}-\sum_{i=1}^{p} \beta_{j} x_{i j}\right)^{2}+\lambda\|\beta\|_{1} .
\end{array}
$$

The optimization problems presented in equations (2) to (5) are standard quadratic programs with convex constraints, and there are a variety of numerical methods to solve them.

The least squares estimation corresponds to an unconstrained minimization problem, the ridge regression adds a smooth, convex $\ell_{2}$ constraint and the Lasso regression a convex but non-smooth $\ell_{1}$ constraint. Least squares favors including as many covariates as possible since it helps reducing the sum of squares. In ridge regression and Lasso regression, non-null coefficients carry a penalty, which helps reducing the value of the coefficients (ridge, Lasso) or reducing the number of the covariates included in the model (Lasso). Notice also that the use of the $\ell_{2}$ penalty in the ridge regression implies that coefficient estimates are not scaleinvariant.

Figure 1 illustrates the geometric intuition underlying the differences between least squares and the two shrinkage regressions, with the ellipses representing the contours of the residual sum of squares. The least squares coefficients, which correspond to the solution of the unconstrained optimization problem, are large relative to those produced by the shrinkage methods. The smooth, convex nature of the $\ell_{2}$ constraint implies that the ridge regression coefficients, albeit small, are not equal to zero. Hence, similarly to least squares, ridge regression, includes all the available covariates and does not yield parsimonious models. 
Figure 1. Geometry of least squares, ridge regression and Lasso regression

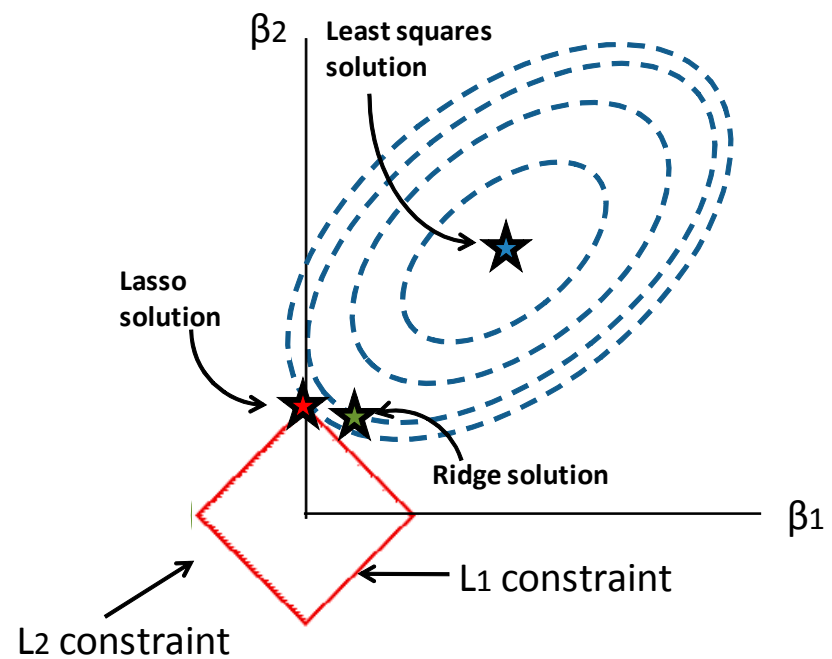

In contrast, the presence of corners in the $\ell_{1}$ constraint increases the chances the ellipses would intersect at the corner, yielding exactly zero coefficients and reducing the number of covariates included in the forecasting model. ${ }^{12}$ The Lasso regression, hence, appears well suited for addressing the model selection challenge posed by the forecasting requirements of stress tests. Note that the Lasso regression performs both the variable selection and parameter estimation simultaneously. Finally, compared with subset selection methods, Lasso exhibits lower variability and cheaper computational costs, especially for high dimensional problems (Hastie, Tibshirani, and Friedman, 2009).

\section{Lasso Regression, Cross-Validation and Consistency}

In Figure 1, the value of the user-specified parameter $t$ is small enough such that the unconstrained optimization solution is not contained within the regions bounded by the $L_{1}$, and $L_{2}$ constraints. Had this parameter been sufficiently large, the ridge regression and Lasso regression solutions would have coincided with the least squares solution. In a Lasso regression, the value of the parameter controls both the size and the number of coefficients, with higher values leading to a greater number of covariates to be included in the linear model. This increases the flexibility of the model and reduces its variance but at the cost of a higher model bias.

Cross-validation, a resampling technique, helps to find a parameter value that ensures a proper balance between bias and variance (or flexibility and interpretability). Crossvalidation selects the best parameter value as the one that minimizes the estimated test error rate of the estimator, in this case the Lasso regression. In the absence of a test set, it is not

\footnotetext{
${ }^{12}$ In general, sparse generalized linear models could be generated by incorporating $L_{1}$ penalty functions, including not only linear regression but also multinomial and survival models. See Hastie et al (2015).
} 
possible to calculate the test error - the average error from using a method to predict the response of a new observation. In cross-validation a subset of the data observations, the training set, is used to estimate (or train) the model, and the remainder observations are held to serve as test set or validation set. The selected test sets serve to provide an estimate of the test error rate. Typically, the measure of the test error is the mean square error (MSE).

The $K$-fold cross-validation method divides the data set randomly into $K$ different subsets, typically five or ten in practical applications. Keeping one of the subsets as the validation set, the model is trained (estimated) over the remaining $K-1$ sets for a range of values of the parameter $t$ (or $\lambda$, if the Lagrangian formulation is used). We repeat this process using each of the $K$ subsets as a validation set, yielding $K$ estimates of the MSE for each parameter value, and its $K$-fold estimate is simply the average value of the $K$ estimates.

The best parameter value is the one yielding the lowest $K$-fold estimate, which we denote as $\lambda$-min in the Lagrangian formulation. It is also typical to report results corresponding to the minimum parameter value such that its $K$-fold estimate does not exceed the minimum $K$-fold estimate by more than one standard error using a lower number of covariates. This parameter estimate is the one-standard error rule parameter, $\lambda-1$ se. The Leave-One-Out cross-validation method is a special case of the $K$-fold cross-validation method. In this case, a sample containing $N$ observations is partitioned exactly into $N$ subsets, which is equivalent to $N$-fold cross-validation.

Since the Lasso biases the coefficients towards zero, the estimates are not consistent. There are ways to address this issue using two-step estimation procedures. In the first step, the Lasso regression selects the covariates in the model. In the second step, only the selected covariates are included in a linear model estimated either by ordinary least squares or by applying the Lasso again. The latter method is known as relaxed Lasso (Meinshausen, 2007), which would be used in the stress test application later. The next section describes some recent applications in finance, economics, and financial networks.

\section{LASSo ApPlications in FinAnCe, Economics, AND FinanCial NetWorks}

Lasso methods, by regularizing least squares estimates to satisfy a $\ell_{1}$ constraint, are very useful for constructing sparse models in high multidimensional data environments. Therefore, there is increased usage of these methods in financial and economic forecasting. ${ }^{13}$

In finance, one active area of research concerns the estimation of stable variance covariance matrices for asset returns, which are necessary inputs for portfolio optimization and asset allocation models. In portfolios including a large number of assets or securities, the returns exhibit strong collinearity, making the sample estimate of the variance covariance matrix and its inverse, the information matrix, highly sensitive to noise and data outliers. Portfolio weights, therefore, may exhibit large changes even if returns are slightly perturbed (Kan and Zhou, 2007), a problem identified long ago (Jorion, 1992; Broadie, 1993).

\footnotetext{
${ }^{13}$ See Fang, Lv, and Qi (2011) for an overall review of sparse modeling in economics.
} 
Lasso constraints can serve to estimate sparse covariance matrices, eliminating the contribution of some of the highly collinear variables, or imposed directly on the portfolio weights. For instance, Brodie, Daubechies, De Mol, Giannone, and Loris (2008), Fan, Zhang, and $\mathrm{Yu}$ (2009), and De Miguel et al (201) require that the sum of the portfolio weights satisfy a $\ell_{1}$ constraint. Moreover, De Miguel et al find that the $\ell_{1}$ - constrained problem is equivalent to the constrained minimum variance portfolio solution of Jagannathan and Ma (2003). More generally, Scherer (2007) shows that optimal portfolio in a Markowitz framework is the solution to a linear regression amenable to solution using Lasso regression. Finally, Bruder, Richard, and Roncalli (2013) explain how the asset selection process benefits from regularization.

Economic applications have centered mainly on the modeling of multivariate time series. Vector autoregressions (VARs) are not well suited for high dimensional problems. To lessen the dimensionality problem, economists have used dynamic factor models (Geweke, 1977; Stock and Watson, 2002) and factor augmented VAR (Bernanke et al, 2005). Lasso methods, however, seem to perform as well as these other models while generating sparser models while bypassing the difficulties in factor interpretation. Results by De Mol, Giannone, and Reichlin (2008) suggest that Lasso regression tend to perform as well as principal components regression when the variables are highly collinear, a typical situation in empirical macroeconomics. Li and Chen (2014) provide evidence that Lasso models tend to outperform factor models.

Straightforward applications of Lasso regressions neglect time dependence in endogenous time series models, an omission that affect the mean square bounds of the estimator. By using Lasso and group-Lasso, Song and Bickel (2010) are able to accommodate time dependence in large VARs. Gefang (2014) exploits time dependence to develop a Bayesian doubly adaptive elastic-net Lasso which allows for grouping effects determined by the data. Kock (2012), Callot and Kock (2014), and Kock and Callot (2015) show that adaptive Lasso estimates parameters consistently, selects the correct sparsity pattern, and it is asymptotically efficient in vector autoregressions.

More recently, Lasso methods serve to construct and estimate financial networks. ${ }^{14}$ In a number of financial networks, the interconnectedness between two financial institutions, or two nodes in the network, is measured either by the correlation between two risk measures, e.g. equity return correlation, or the risk contribution of one institution to the risk of another. In these networks, the systemic risk of a financial institution is set proportional to a measure of centrality, i.e. the number of connections to other institutions in the system or the number of possible paths from one institution to another that include the institution, among others.

Again, the curse of dimensionality poses problems. When the analysis includes a large number of institutions, estimating correlations requires as an input a stable variancecovariance matrix. Furthermore, correlation networks may show too much

\footnotetext{
14 This development is a natural extension of statistics applications of the Lasso in high dimensional graphs (Meinshausen and Buhlmann, 2006).
} 
interconnectedness, as the correlation matrix is quite dense. As in the case of portfolio optimization, Lasso methods are able to generate sparse correlation matrices. For example, Chan-Lau, Chuang, Duan, and Sun (2015) use economic priors and Lasso restrictions to produce relatively sparse but fully connected financial networks, where interconnectedness in the network arises from forward-looking default correlations. Upon constructing the network, assessing the systemic risk of individual firms is a straightforward exercise.

In other instances, the risk contribution of one institution is an output from an econometric model that incorporates a large number of covariates, which presents the curse of dimensionality problem. For example, in the global banking network described in Demirer, Diebold, Liu, and Yilmaz (2015), the value of the edge connecting one bank to another is proportional to its contribution to the variance decomposition of the volatility of equity returns of the latter. With hundreds of banks in the network, a Lasso reduced-dimensional VAR helps reducing the high dimensionality of the problem, making feasible obtaining the variance decomposition.

Before moving to the next section, which applies lasso regressions to forecast probabilities of default, it is important to note one important caveat raised by Hansen (2013). The prediction advantages of Lasso-based models seem to vanish when the number of covariates is small relative to the sample size. As the earlier discussion has emphasized, however, this is not the situation typically encountered in a stress test.

\section{A Stress Test Application: Forecasting Probabilities of Default}

This section puts into practice the discussion above, using Lasso regressions to construct forecasting models for the median one-year probabilities of default (PD) in ten different industrial sectors in an advanced emerging market economy.

The sectors included are basic materials, communications, consumer cyclicals, consumer non-cyclicals, diversified industries, energy, financials, industrials, technology and utilities. The monthly median PD series data came from the CRI database maintained by the Risk Management Institute, National University of Singapore (Duan and Van Laere, 2012), and accessed on April 30, 2014. The data covers the period December 1990 - February 2014. ${ }^{15}$

There are thirteen domestic primary variables including the exchange rate vis-à-vis the U.S. dollar, the nominal effective exchange rate, the domestic policy rate, the consumer price index, the real GDP growth rate, the unemployment rate, the total amount of credit in the economy, the money market rate, the 3-month Treasury bill rate, the bank deposit rate, the bank lending rate, and the 10-year Treasury bond rate. The domestic variables are complemented by five international variables: the U.S. real GDP, the China real GDP, the U.S. policy rate, the U.S. consumer price index, and a commodity price index. The data, collected at a quarterly frequency, covers the period 1990 Q1 - 2013 Q4.

\footnotetext{
${ }^{15}$ On the methodology for constructing the PD series, see Duan, Sun, and Wang (2012) .
} 
We fitted the equation below for each sectoral median PD using both Lasso and relaxed Lasso and 10-fold cross-validation:

$$
\log \left(\frac{P D_{i, t}}{1-P D_{i, t}}\right)=\alpha_{i}+\sum_{k=1}^{p} \sum_{\ell=0}^{4} X_{k, t-\ell}+\varepsilon_{i, t}, i=\operatorname{sector} 1 \text { to } 10
$$

where $\alpha_{i}$ is the constant term, $X_{k, t-\ell}$ is the value of the covariate $k$ lagged by $\ell$ periods, and $\varepsilon_{i, t}$ is the error term. Because the Lasso constraint applies to the norm of the coefficients, it is necessary to standardize the covariates otherwise the coefficients of covariates with smaller measurement units may be unfairly penalized. The standardization procedure consists on calculating the covariate's Z-score by centering it covariate on its mean and normalized by its standard deviation.

In this application the number of potential covariates, $p$, is equal to ninety excluding the intercept, and the number of observations, $n$, is at most one hundred, a situation well suited for Lasso estimation. With $p \sim n$, ordinary least squares estimates would exhibit high sensitivity to outliers (Hastie, Tibshirani, and Friedman, 2008). Pre-selecting the variables and choosing the number of lags would require a detailed knowledge of the drivers of default in different sectors. Since the median PD is the variable of interest, expert judgment may require understanding the differences in PD dynamics of individual firms within a sector.

The Lasso estimation includes all ninety covariates while the relaxed Lasso only includes the covariates with non-zero coefficients of the Lasso $\lambda$-min specification. This two-step procedure ensures the relaxed Lasso yields at most the same number of non-zero coefficients as the Lasso and likely less for the $\lambda$-1 se specification. The estimation used the $\mathrm{R}$ implementation of the coordinate descent algorithm of Friedman, Hastie, and Tibshirani (2010).

Figure 2, and Tables 1 and 2 illustrate the differences between the Lasso and relaxed Lasso estimations. Figure 2 shows the MSEs, or a measure of the models' out-of-sample forecasting performance, for different values of the $\lambda$ parameter, expressed in natural logarithms in the lower horizontal axis, while the upper horizontal axis reports the corresponding number of non-zero coefficients identified by the Lasso and relaxed Lasso methods. The leftmost vertical dashed line in the figures correspond to the $\lambda$-min parameter, i.e. the parameter that yields the minimum MSE, while the rightmost vertical dashed line to the $\lambda$-1se parameter, i.e. the parameter that yields a MSE exactly 1 standard deviation above the minimum MSE using a lower number of covariates.

The Lasso reduces the dimensionality of the problem significantly, with the number of covariates ranging from four to the mid-20s for the $\lambda$-min specification, and from zero to slightly below twenty for the $\lambda$-1 se specification, results similar to those obtained using the relaxed Lasso. In the worst case scenario, from a dimensionality perspective, the Lasso and relaxed Lasso retain only about one quarter of the potential covariates. With both methods, the $\lambda$-min specification has a lower variance than the $\lambda$-1 se specification due to its higher number of non-zero coefficients. 
Figure 2. Lasso and relaxed Lasso, mean squared errors (MSEs)

Lasso regression, left side panels; relaxed lasso regressions, right side panels. In each panel, mean squared errors, red line, bounded by +/- 1 standard deviation lines, vertical axis; upper horizontal axis indicates number of non-zero coefficients associated with a given value of $\log (\lambda)$. Leftmost discontinuous vertical line corresponds to the MSE of $\lambda$-min; rightmost discontinuous vertical line to the MSE of the $\lambda$ - 1 se.

品

Basic Materials: Lasso
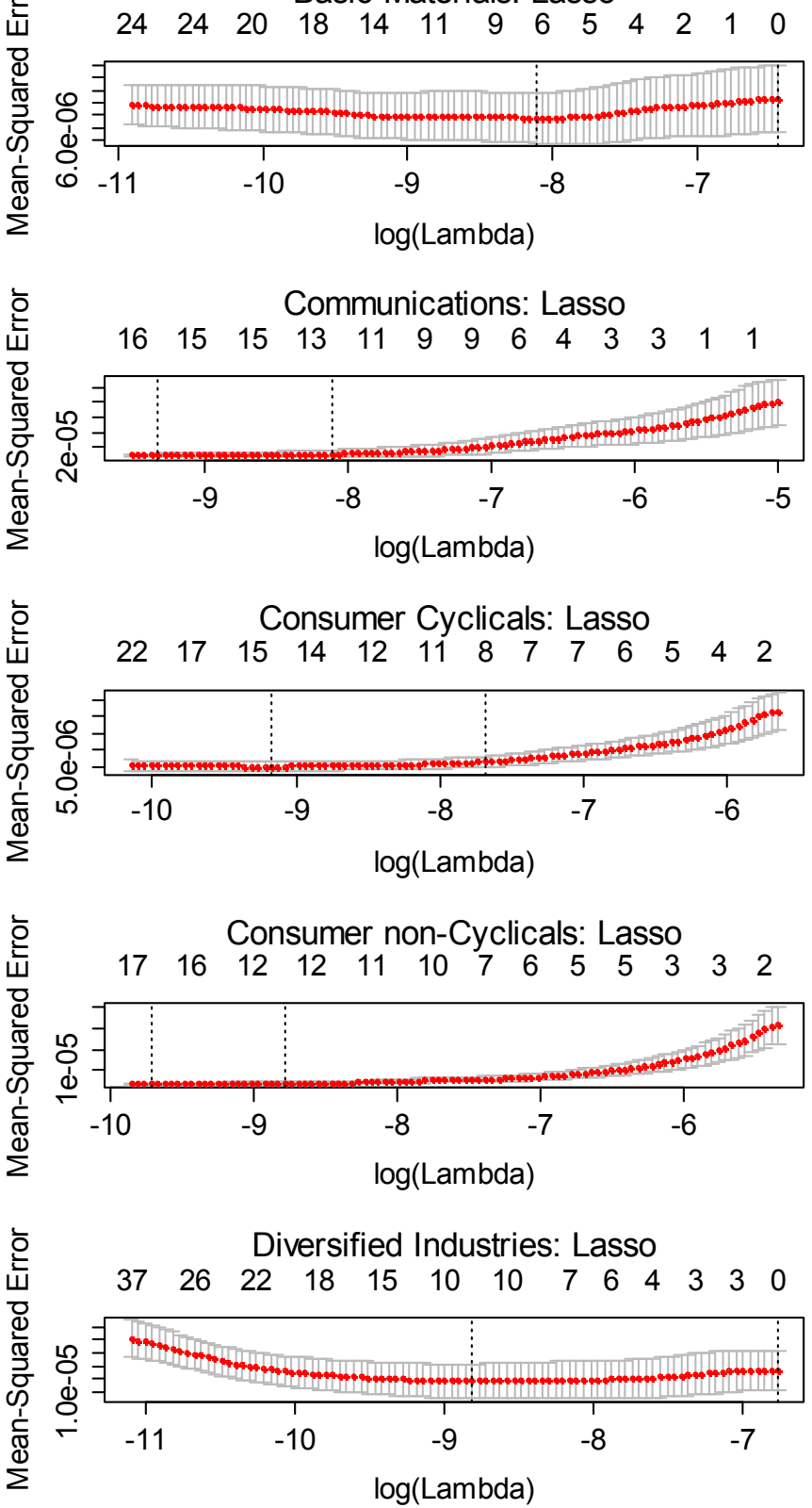

Source: Author's calculations.
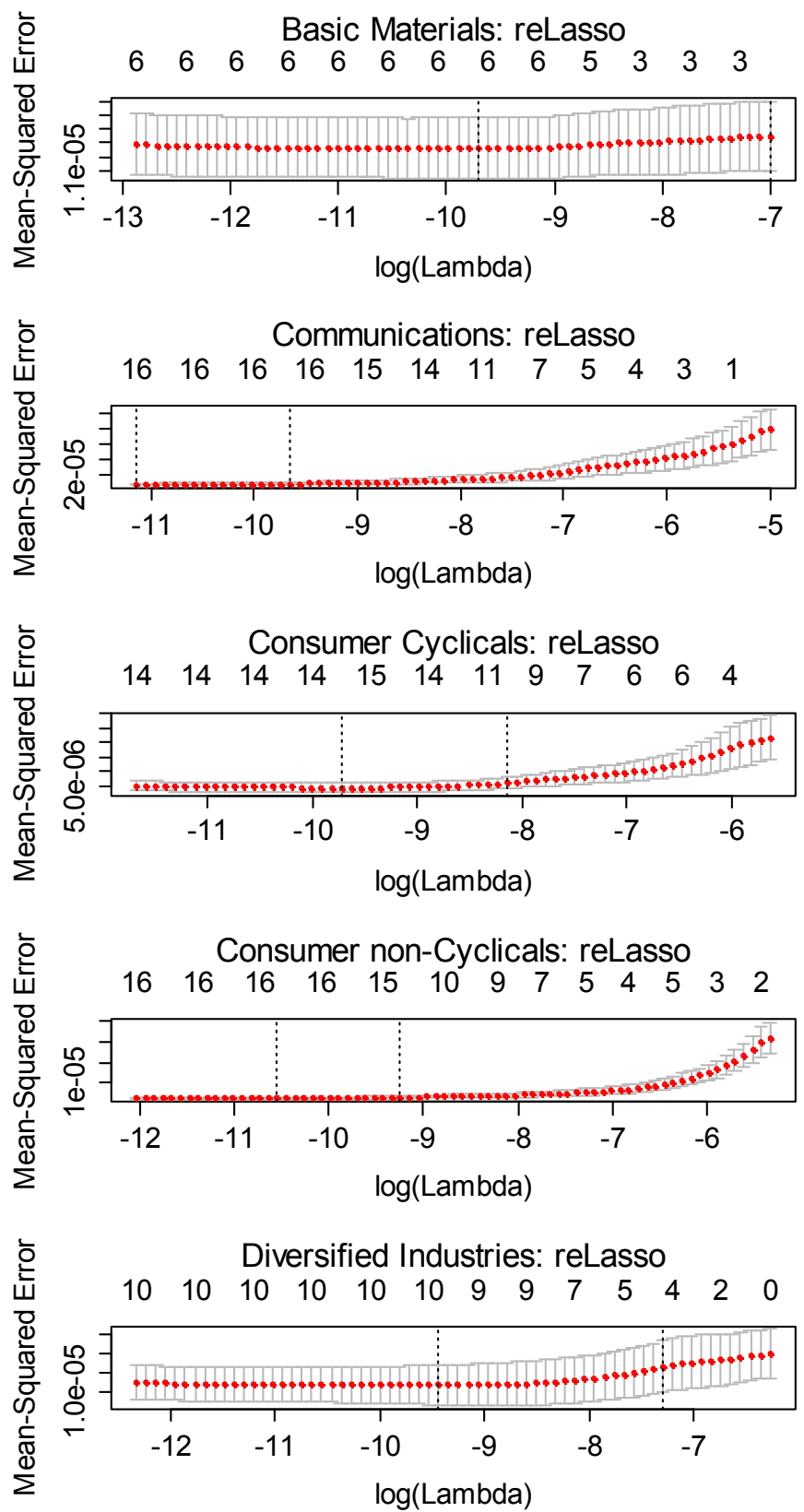
Figure 2 (continued). Lasso and relaxed Lasso, mean squared errors (MSEs)

Lasso regression, left side panels; relaxed lasso regressions, right side panels. In each panel, mean squared errors, red line, bounded by +/- 1 standard deviation lines, vertical axis; upper horizontal axis indicates number of non-zero coefficients associated with a given value of $\log (\lambda)$. Leftmost discontinuous vertical line corresponds to the MSE of $\lambda$-min; rightmost discontinuous vertical line to the MSE of the $\lambda$-1se.

늠

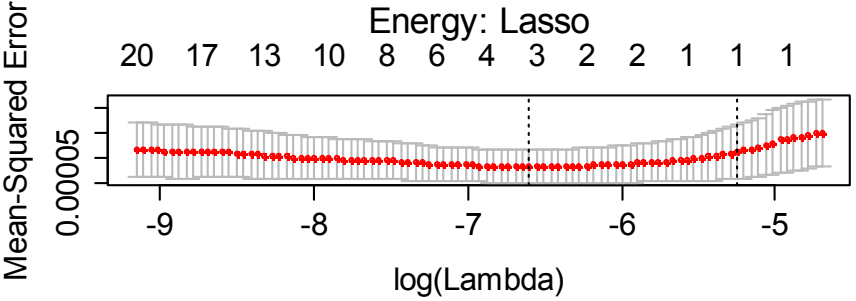

는

Financials: Lasso
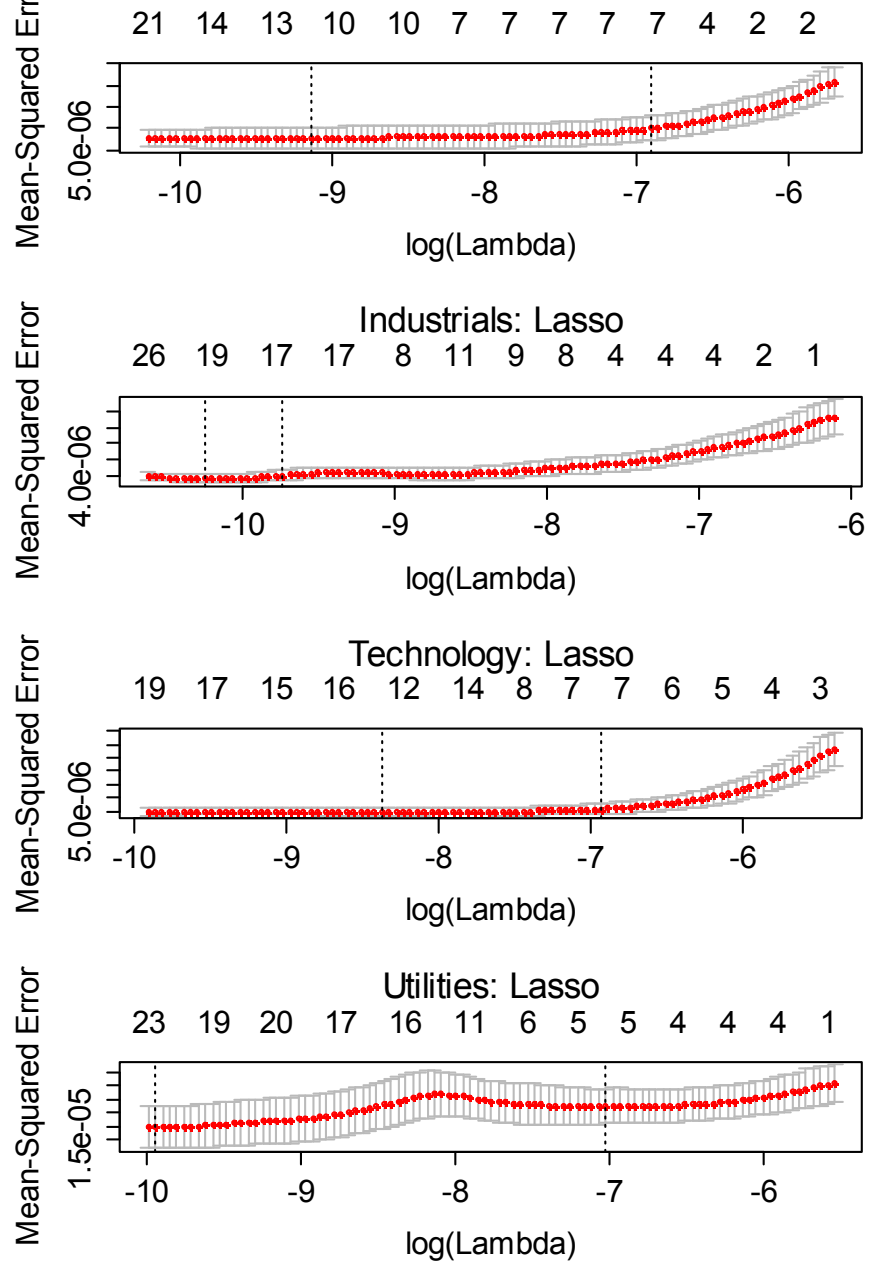

Source: Author's calculations.

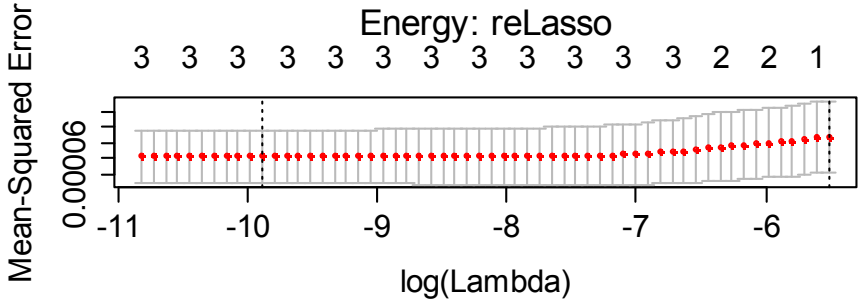

Financials: reLasso

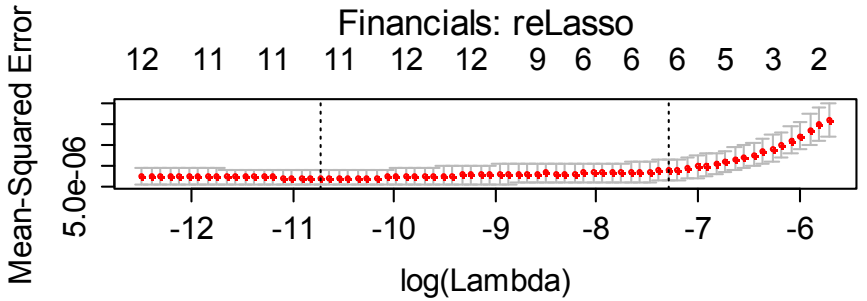

Industrials: reLasso
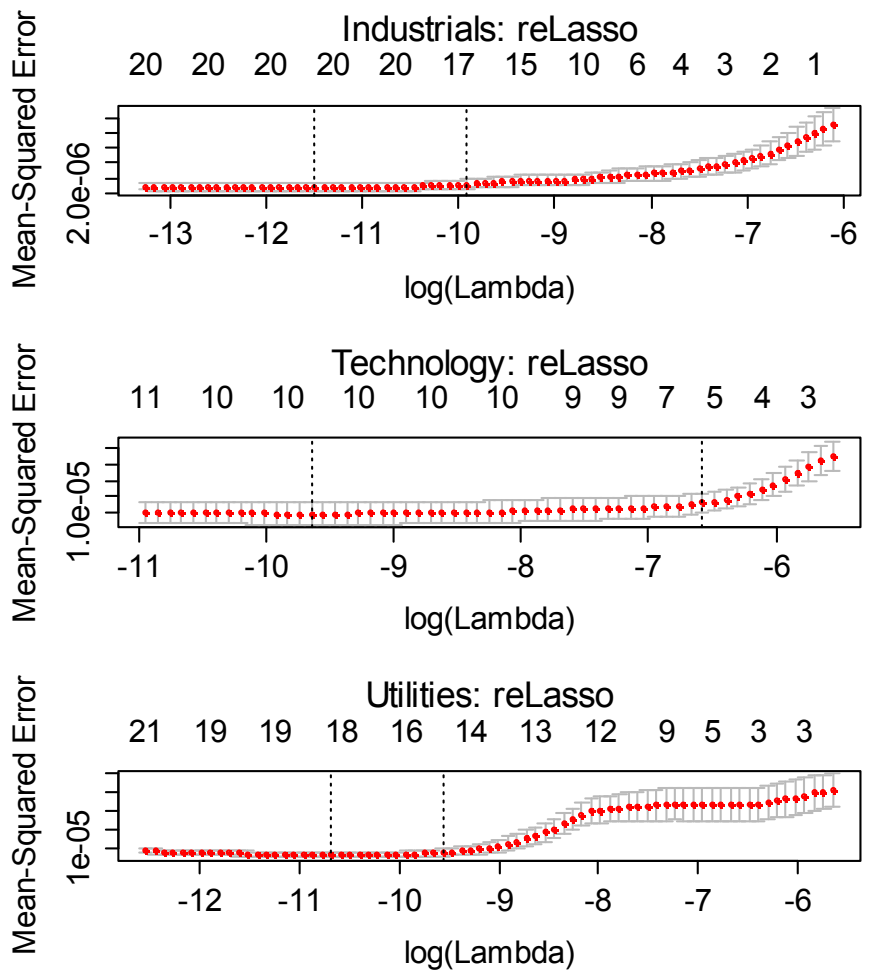
Table 1 indicates that the relaxed Lasso $\lambda$-min specification tends to retain all the non-zero coefficients identified by the Lasso, suggesting the former method does a good job in selecting the covariates of interest. The magnitude of the relaxed Lasso coefficients is typically larger than that of the Lasso coefficients, reflecting what Hastie, Tibshirani, and Friedman (2008) described as reduced noise owing to the presence of a lower number of covariates.

Lasso methods do simplify the task of variable selection in forecasting models. Table 1 also shows that the number of relevant economic and financial covariates is quite small relative to the initial set of primary covariates. No more than ten covariates of the original set of eighteen covariates, including up to four lags, are useful for predicting the median PD in each sector in the $\lambda$-min model specifications, with less than six variables included for many of the sectoral forecasting models.

As Table 2 shows, it is possible to generate more sparse models when the $\lambda$ - 1 se specification is used, sacrificing some variance at the expense of reducing the bias by further limiting the number of covariates. In this case, the number of covariates needed is typically four or five though in some sectors it is still necessary to include as many as ten variables. For some sectors, however, using the one standard rule implied by the $\lambda$-1 se parameter yields models with just the intercept as an explanatory variable. In this specific example, it may be justified to use the forecasting models generated using the $\lambda$-min parameters since the presence of six to ten covariates is manageable.

There is not a close correspondence between the non-zero coefficients in the Lasso and relaxed Lasso specifications when the $\lambda$ parameter is set equal to the $\lambda-1$ se value. This is not surprising since the set of initial covariates in the relaxed Lasso regression corresponded to those obtained in the Lasso regression with parameter value equal to $\lambda$-min, which is quite different from the set yielded by the Lasso regression with parameter value equal to $\lambda-1$ se.

The final observation is that the tables do not report standard errors for the coefficients, as it is typical in econometric studies. Although the standard errors could be calculated using, among other techniques, nonparametric bootstrap (Hastie, Tibshirani, and Wainwright, 2015), there are strong arguments against calculating them (Goeman, Meijer, and Chaturvedi, 2014).

In order to improve the out-of-sample forecasting of the model, Lasso-type estimators force the value of the coefficients towards zero, improving the variance of the model at the expense of obtaining biased coefficients. Since it is not possible to obtain reliable unbiased coefficient estimates, even bootstrapping confidence intervals would convey an unjustified sense of the precision of the estimates. A possible solution, in low dimensional problems, is to use Lassotype estimators only at the model selection stage. Afterwards, the estimation of the final forecasting model uses traditional statistical techniques. 
Table 1. Lasso and relaxed lasso, coefficient estimates, $\lambda$-min specification

\begin{tabular}{|c|c|c|c|c|c|c|c|c|c|c|}
\hline \multirow[b]{3}{*}{ Variables } & \multicolumn{10}{|c|}{ Panel A: Basic Materials } \\
\hline & \multirow{2}{*}{\multicolumn{5}{|c|}{$\begin{array}{l}\text { Lasso } \\
\text { Number of lags }\end{array}$}} & \multirow{2}{*}{\multicolumn{5}{|c|}{$\begin{array}{l}\text { Relaxed Lasso } \\
\text { Number of lags }\end{array}$}} \\
\hline & 0 & Ne & & & & 0 & & & & 4 \\
\hline Exchange rate vic_ì-victhe $\| \mathrm{s}$ dellar & 0 & 0 & 0 & 0 & 0 & 0 & 0 & 0 & 0 & 0 \\
\hline Exchange rate vis-à-vis the U.S. dollar & 0 & 0 & 0 & 0 & 0 & 0 & 0 & 0 & 0 & $\begin{array}{c}0 \\
-9.04 E-05\end{array}$ \\
\hline Real effective exchange rate & 0 & 0 & 0 & 0 & $2.26 \mathrm{E}-05$ & 0 & 0 & U & 0 & $-9.04 \mathrm{t}-05$ \\
\hline Policy rate & 0 & 0 & 0 & 0 & 0 & 0 & 0 & 0 & 0 & 0 \\
\hline Consumer price index & 0 & 0 & 0 & 0 & 0 & 0 & 0 & 0 & 0 & 0 \\
\hline Real GDP growth rate & 0 & 0 & 0 & 0 & 0 & 0 & 0 & 0 & 0 & 0 \\
\hline Money market rate & 0 & 0 & 0 & 0 & 0 & 0 & 0 & 0 & 0 & 0 \\
\hline 3-month Treasury bill rate & 0 & 0 & 0 & 0 & 0 & 0 & 0 & 0 & 0 & 0 \\
\hline Bank deposit rate & 0 & 0 & 0 & 0 & 0 & 0 & 0 & 0 & 0 & 0 \\
\hline Bank lending rate & 0 & 0 & 0 & 0 & 0 & 0 & 0 & 0 & 0 & 0 \\
\hline 10-year Treasury bond yield & 0 & 0.000568 & 0.000382 & 0 & 0 & 0 & 3.73E-04 & 4.62E-05 & 0 & 0 \\
\hline Unemployment rate & 0 & 0 & 0 & 0 & 0 & 0 & 0 & 0 & 0 & 0 \\
\hline U.S. real GDP growth rate & 0 & 0 & 0 & 0 & 0 & 0 & 0 & 0 & 0 & 0 \\
\hline People's Republic of China real growth rate & 0 & 0 & 0 & 0 & 0 & 0 & 0 & 0 & 0 & 0 \\
\hline U.S. policy rate & -0.00053 & 0 & 0 & 0 & 0 & $-8.78 \mathrm{E}-05$ & 0 & 0 & 0 & 0 \\
\hline Credit, growth rate & 0 & 0 & 0 & 0 & 0 & 0 & 0 & 0 & 0 & 0 \\
\hline U.S. consumer price index & 0 & 0 & 4.72E-06 & 3.47E-06 & 0 & 0 & 0 & $6.73 \mathrm{E}-06$ & 2.35E-06 & 0 \\
\hline Commodity price index & 0 & 0 & 0 & 0 & 0 & 0 & 0 & 0 & 0 & 0 \\
\hline Nominal effective exchange rate & 0 & 0 & 0 & 0 & 0 & 0 & 0 & 0 & 0 & 0 \\
\hline
\end{tabular}

\begin{tabular}{|c|c|c|c|c|c|c|c|c|c|c|}
\hline \multirow{3}{*}{ Variables } & \multicolumn{10}{|c|}{ Panel B: Communications } \\
\hline & \multicolumn{5}{|c|}{$\begin{array}{l}\text { Lasso } \\
\text { Number of lags }\end{array}$} & \multicolumn{5}{|c|}{$\begin{array}{l}\text { Relaxed Lasso } \\
\text { Number of lags }\end{array}$} \\
\hline & 0 & 1 & 2 & 3 & 4 & 0 & 1 & 2 & 3 & 4 \\
\hline Exchange rate vis-à-vis the U.S. dollar & 0.001095 & 0 & 0 & 0.000161 & 0 & 0.000881 & 0 & 0 & 0.000693 & 0 \\
\hline Real effective exchange rate & -0.00014 & 0 & 0.00018 & 0 & 0 & -0.00017 & 0 & 0.000246 & 0 & 0 \\
\hline Policy rate & -0.00135 & -0.00064 & 0 & 0 & 0 & -0.00182 & -0.00048 & 0 & 0 & 0 \\
\hline Consumer price index & 0 & 0 & 0 & 0 & 0 & 0 & 0 & 0 & 0 & 0 \\
\hline Real GDP growth rate & 0 & 0 & 0 & 0 & 0 & 0 & 0 & 0 & 0 & 0 \\
\hline Money market rate & 0 & 0 & 0 & 0 & 0 & 0 & 0 & 0 & 0 & 0 \\
\hline 3-month Treasury bill rate & 0 & 0 & 0 & 0 & 0 & 0 & 0 & 0 & 0 & 0 \\
\hline Bank deposit rate & 0 & 0 & 0 & 0 & 0 & 0 & 0 & 0 & 0 & 0 \\
\hline Bank lending rate & 0 & 0 & 0 & 0 & 0 & 0 & 0 & 0 & 0 & 0 \\
\hline 10-year Treasury bond yield & 0.001068 & 0 & 0.000911 & 0.000787 & 0.002025 & 0.001189 & 0 & 0.001298 & 0.000593 & 0.001817 \\
\hline Unemployment rate & 0.000671 & 0.000323 & 0 & -0.00047 & -0.00055 & 0.000729 & 0.000483 & 0 & -0.00044 & -0.0007 \\
\hline U.S. real GDP growth rate & 0 & 0 & 0 & 0 & 0 & 0 & 0 & 0 & 0 & 0 \\
\hline People's Republic of China real growth rate & 0 & 0 & 0 & 0 & 0 & 0 & 0 & 0 & 0 & 0 \\
\hline U.S. policy rate & 0 & 0 & 0 & 0 & 0.002177 & 0 & 0 & 0 & 0 & 0.002586 \\
\hline Credit, growth rate & 0 & 0 & 0 & 0 & 0 & 0 & 0 & 0 & 0 & 0 \\
\hline U.S. consumer price index & 0 & 0 & 0 & 0 & 0 & 0 & 0 & 0 & 0 & 0 \\
\hline Commodity price index & 0 & 0 & 0 & 0 & 0 & 0 & 0 & 0 & 0 & 0 \\
\hline Nominal effective exchange rate & 0 & 0 & 4.16E-07 & 0 & 0 & 0 & 0 & $2.82 \mathrm{E}-06$ & 0 & 0 \\
\hline
\end{tabular}

Source: Author's calculations. 
Table 1. Lasso and relaxed lasso, coefficient estimates, $\lambda$-min specification (continued)

\begin{tabular}{|c|c|c|c|c|c|c|c|c|c|c|}
\hline \multirow{3}{*}{ Variables } & \multicolumn{10}{|c|}{ Panel C: Consumer Cyclicals } \\
\hline & \multicolumn{5}{|c|}{$\begin{array}{l}\text { Lasso } \\
\text { Number of lags }\end{array}$} & \multicolumn{5}{|c|}{$\begin{array}{l}\text { Relaxed Lasso } \\
\text { Number of lags }\end{array}$} \\
\hline & 0 & 1 & 2 & 3 & 4 & 0 & 1 & 2 & 3 & 4 \\
\hline Exchange rate vis-à-vis the U.S. dollar & 0.000556 & 0 & 0 & 0 & 0 & 0.00053 & 0 & 0 & 0 & 0 \\
\hline Real effective exchange rate & 0 & 0 & 0 & 0 & 0 & 0 & 0 & 0 & 0 & 0 \\
\hline Policy rate & 0 & 0 & 0 & 0 & 0 & 0 & 0 & 0 & 0 & 0 \\
\hline Consumer price index & 0 & 0 & 0 & 0 & 0 & 0 & 0 & 0 & 0 & 0 \\
\hline Real GDP growth rate & 0 & 0 & 0 & 0 & 0 & 0 & 0 & 0 & 0 & 0 \\
\hline Money market rate & -0.00036 & 0 & 0 & 0 & 0 & -0.00043 & 0 & 0 & 0 & 0 \\
\hline 3-month Treasury bill rate & 0 & 0 & 0 & 0 & 0 & 0 & 0 & 0 & 0 & 0 \\
\hline Bank deposit rate & 0 & 0 & 0 & 0 & 0 & 0 & 0 & 0 & 0 & 0 \\
\hline Bank lending rate & 0 & 0 & 0 & 0 & 0 & 0 & 0 & 0 & 0 & 0 \\
\hline 10-year Treasury bond yield & 0.00038 & 0.000768 & 0.000923 & $5.93 \mathrm{E}-05$ & 0.001051 & 0.000479 & 0.000753 & 0.001039 & $9.22 \mathrm{E}-06$ & 0.001073 \\
\hline Unemployment rate & 0 & $-6.32 \mathrm{E}-06$ & $-9.34 \mathrm{E}-05$ & -0.00019 & -0.00022 & 0 & $-1.73 E-05$ & $-7.07 E-05$ & -0.00019 & -0.00022 \\
\hline U.S. real GDP growth rate & 0 & 0 & 0 & 0 & 0 & 0 & 0 & 0 & 0 & 0 \\
\hline People's Republic of China real growth rate & 0 & 0 & 0 & 0 & 0 & 0 & 0 & 0 & 0 & 0 \\
\hline U.S. policy rate & 0 & 0 & 0 & 0.000138 & $5.14 \mathrm{E}-05$ & 0 & 0 & 0 & 0.000192 & $5.82 \mathrm{E}-05$ \\
\hline Credit, growth rate & 0 & 0 & 0 & 0 & 0 & 0 & 0 & 0 & 0 & 0 \\
\hline U.S. consumer price index & 0 & 0 & $1.31 \mathrm{E}-06$ & 0 & $3.13 \mathrm{E}-06$ & 0 & 0 & 1.95E-06 & 0 & $3.74 \mathrm{E}-06$ \\
\hline Commodity price index & 0 & 0 & 0 & 0 & 0 & 0 & 0 & 0 & 0 & 0 \\
\hline Nominal effective exchange rate & 0 & 0 & 0 & 0 & 0 & 0 & 0 & 0 & 0 & 0 \\
\hline
\end{tabular}

\begin{tabular}{|c|c|c|c|c|c|c|c|c|c|c|}
\hline \multirow{3}{*}{ Variables } & \multicolumn{10}{|c|}{ Panel D: Consumer non-Cyclicals } \\
\hline & \multicolumn{5}{|c|}{$\begin{array}{c}\text { Lasso } \\
\text { Number of lags }\end{array}$} & \multicolumn{5}{|c|}{$\begin{array}{l}\text { Relaxed Lasso } \\
\text { Number of lags }\end{array}$} \\
\hline & 0 & 1 & 2 & 3 & 4 & 0 & 1 & 2 & 3 & 4 \\
\hline Exchange rate vis-à-vis the U.S. dollar & 0.001142 & 0 & 0 & 0 & 0.001084 & 0.001332 & 0 & 0 & 0 & 0.001311 \\
\hline Real effective exchange rate & 0 & 2.64E-05 & $6.61 \mathrm{E}-05$ & 0 & 0 & 0 & $5.48 \mathrm{E}-05$ & $8.34 \mathrm{E}-05$ & 0 & 0 \\
\hline Policy rate & 0 & 0 & 0 & 0 & 0 & 0 & 0 & 0 & 0 & 0 \\
\hline Consumer price index & 0 & 0 & 0 & 0 & 0 & 0 & 0 & 0 & 0 & 0 \\
\hline Real GDP growth rate & 0 & 0 & 0 & 0 & 0 & 0 & 0 & 0 & 0 & 0 \\
\hline Money market rate & $-2.54 \mathrm{E}-05$ & 0 & 0 & 0 & 0 & -0.0001 & 0 & 0 & 0 & 0 \\
\hline 3-month Treasury bill rate & 0 & 0 & 0 & 0 & 0 & 0 & 0 & 0 & 0 & 0 \\
\hline Bank deposit rate & 0 & 0 & 0 & 0 & 0 & 0 & 0 & 0 & 0 & 0 \\
\hline Bank lending rate & 0 & 0 & 0 & 0 & 0 & 0 & 0 & 0 & 0 & 0 \\
\hline 10-year Treasury bond yield & 0.000196 & 0.000467 & 0 & 0.000626 & 0.001248 & 0.000145 & 0.000634 & 0 & 0.000618 & 0.001154 \\
\hline Unemployment rate & 0.000405 & 0 & $-2.75 \mathrm{E}-05$ & -0.00041 & -0.00018 & 0.00046 & 0 & $-6.71 E-05$ & -0.00042 & -0.00022 \\
\hline U.S. real GDP growth rate & 0 & 0 & 0 & 0 & 0 & 0 & 0 & 0 & 0 & 0 \\
\hline People's Republic of China real growth rate & 0 & 0 & 0 & 0 & 0 & 0 & 0 & 0 & 0 & 0 \\
\hline U.S. policy rate & 0 & 0 & 0.0001 & 0.000364 & 0 & 0 & 0 & 8.79E-05 & 0.000502 & 0 \\
\hline Credit, growth rate & 0 & 0 & 0 & 0 & 0 & 0 & 0 & 0 & 0 & 0 \\
\hline U.S. consumer price index & $-2.27 \mathrm{E}-06$ & 0 & 0 & 0 & 0 & $-3.33 E-06$ & 0 & 0 & 0 & 0 \\
\hline Commodity price index & 0 & 0 & 0 & 0 & 0 & 0 & 0 & 0 & 0 & 0 \\
\hline Nominal effective exchange rate & 0 & 0 & 0 & 0 & 0 & 0 & 0 & 0 & 0 & 0 \\
\hline
\end{tabular}

Source: Author's calculations. 
Table 1. Lasso and relaxed lasso, coefficient estimates, $\lambda$-min specification (continued)

\begin{tabular}{|c|c|c|c|c|c|c|c|c|c|c|}
\hline \multirow{3}{*}{ Variables } & \multicolumn{10}{|c|}{ Panel E: Diversified Industrials } \\
\hline & \multicolumn{5}{|c|}{$\begin{array}{l}\text { Lasso } \\
\text { Number of lags }\end{array}$} & \multicolumn{5}{|c|}{$\begin{array}{l}\text { Relaxed Lasso } \\
\text { Number of lags }\end{array}$} \\
\hline & 0 & 1 & 2 & 3 & 4 & 0 & 1 & 2 & 3 & 4 \\
\hline Exchange rate vis-à-vis the U.S. dollar & 0 & 0 & 0 & 0 & 0 & 0 & 0 & 0 & 0 & 0 \\
\hline Real effective exchange rate & 0 & 0 & 0 & 3.32E-05 & 0.000101 & 0 & 0 & 0 & 4.18E-05 & 0.000148 \\
\hline Policy rate & 0 & 0 & 0 & 0 & 0 & 0 & 0 & 0 & 0 & 0 \\
\hline Consumer price index & 0 & 0 & 0 & 0 & 0 & 0 & 0 & 0 & 0 & 0 \\
\hline Real GDP growth rate & 0 & 0 & 0 & 0 & 0 & 0 & 0 & 0 & 0 & 0 \\
\hline Money market rate & 0 & 0 & 0 & 0 & 0 & 0 & 0 & 0 & 0 & 0 \\
\hline 3-month Treasury bill rate & 0 & 0 & 0 & 0 & 0 & 0 & 0 & 0 & 0 & 0 \\
\hline Bank deposit rate & 0 & 0.000532 & 0 & 0 & 0.000411 & 0 & 0.000584 & 0 & 0 & 0.000678 \\
\hline Bank lending rate & 0 & 0 & 0 & 0 & 0 & 0 & 0 & 0 & 0 & 0 \\
\hline 10-year Treasury bond yield & 0.000174 & 0.000966 & 0 & 0 & 0.000297 & 0.000363 & 0.000703 & 0 & 0 & 0.000479 \\
\hline Unemployment rate & 0 & 0.000252 & 0 & 0 & 0 & 0 & 0.000467 & 0 & 0 & 0 \\
\hline U.S. real GDP growth rate & 0 & 0 & 0 & 0 & 0 & 0 & 0 & 0 & 0 & 0 \\
\hline People's Republic of China real growth rate & 0 & 0 & 0 & 0 & 0 & 0 & 0 & 0 & 0 & 0 \\
\hline U.S. policy rate & -0.00014 & 0 & 0 & 0 & 0 & $-1.85 \mathrm{E}-05$ & 0 & 0 & 0 & 0 \\
\hline Credit, growth rate & 0 & 0 & 0 & 0 & 0 & 0 & 0 & 0 & 0 & 0 \\
\hline U.S. consumer price index & 0 & $1.48 \mathrm{E}-05$ & 0 & 0 & 0 & 0 & $1.83 \mathrm{E}-05$ & 0 & 0 & 0 \\
\hline Commodity price index & 0 & 0 & 0 & 0 & 0 & 0 & 0 & 0 & 0 & 0 \\
\hline Nominal effective exchange rate & 0 & 0 & 0 & 0 & 0 & 0 & 0 & 0 & 0 & 0 \\
\hline
\end{tabular}

\begin{tabular}{|c|c|c|c|c|c|c|c|c|c|c|}
\hline \multirow{3}{*}{ Variables } & \multicolumn{10}{|c|}{ Panel E: Energy } \\
\hline & \multicolumn{5}{|c|}{$\begin{array}{l}\text { Lasso } \\
\text { Number of lags }\end{array}$} & \multicolumn{5}{|c|}{$\begin{array}{l}\text { Relaxed Lasso } \\
\text { Number of lags }\end{array}$} \\
\hline & 0 & 1 & 2 & 3 & 4 & 0 & 1 & 2 & 3 & 4 \\
\hline Exchange rate vis-à-vis the U.S. dollar & 0.000285 & 0 & 0 & 0 & 0 & 0.003426 & 0 & 0 & 0 & 0 \\
\hline Real effective exchange rate & 0 & 0 & 0 & 0 & 0 & 0 & 0 & 0 & 0 & 0 \\
\hline Policy rate & 0 & 0 & 0 & 0 & 0 & 0 & 0 & 0 & 0 & 0 \\
\hline Consumer price index & 0 & 0 & 0 & 0 & 0 & 0 & 0 & 0 & 0 & 0 \\
\hline Real GDP growth rate & 0 & 0 & 0 & 0 & 0 & 0 & 0 & 0 & 0 & 0 \\
\hline Money market rate & 0 & 0 & 0 & 0 & 0 & 0 & 0 & 0 & 0 & 0 \\
\hline 3-month Treasury bill rate & 0 & 0 & 0 & 0 & 0 & 0 & 0 & 0 & 0 & 0 \\
\hline Bank deposit rate & 0 & 0 & 0 & 0 & 0 & 0 & 0 & 0 & 0 & 0 \\
\hline Bank lending rate & 0 & 0 & 0 & 0 & 0 & 0 & 0 & 0 & 0 & 0 \\
\hline 10-year Treasury bond yield & 0 & 0 & 0 & 0 & 0.004037 & 0 & 0 & 0 & 0 & 0.001039 \\
\hline Unemployment rate & 0 & 0 & 0 & 0 & 0 & 0 & 0 & 0 & 0 & 0 \\
\hline U.S. real GDP growth rate & 0 & 0 & 0 & 0 & 0 & 0 & 0 & 0 & 0 & 0 \\
\hline People's Republic of China real growth rate & 0 & 0 & 0 & 0 & 0 & 0 & 0 & 0 & 0 & 0 \\
\hline U.S. policy rate & 0 & 0 & 0 & 0 & 0.000776 & 0 & 0 & 0 & 0 & 0.000808 \\
\hline Credit, growth rate & 0 & 0 & 0 & 0 & 0 & 0 & 0 & 0 & 0 & 0 \\
\hline U.S. consumer price index & 0 & 0 & 0 & 0 & 0 & 0 & 0 & 0 & 0 & 0 \\
\hline Commodity price index & 0 & 0 & 0 & 0 & 0 & 0 & 0 & 0 & 0 & 0 \\
\hline Nominal effective exchange rate & 0 & 0 & 0 & 0 & 0 & 0 & 0 & 0 & 0 & 0 \\
\hline
\end{tabular}

Source: Author's calculations. 
Table 1. Lasso and relaxed lasso, coefficient estimates, $\lambda$-min specification (continued)

\begin{tabular}{|c|c|c|c|c|c|c|c|c|c|c|}
\hline \multirow{3}{*}{ Variables } & \multicolumn{10}{|c|}{ Panel G: Financials } \\
\hline & \multicolumn{5}{|c|}{$\begin{array}{c}\text { Lasso } \\
\text { Number of lags }\end{array}$} & \multicolumn{5}{|c|}{$\begin{array}{l}\text { Relaxed Lasso } \\
\text { Number of lags }\end{array}$} \\
\hline & 0 & 1 & 2 & 3 & 4 & 0 & 1 & 2 & 3 & 4 \\
\hline Exchange rate vis-à-vis the U.S. dollar & 0.001571 & 0.000305 & 0.000231 & 0 & 0.001056 & 0.001373 & 0.00052 & 0.000651 & 0 & 0.000756 \\
\hline Real effective exchange rate & 0 & 0 & 0 & 0 & 0 & 0 & 0 & 0 & 0 & 0 \\
\hline Policy rate & 0 & 0 & 0 & 0 & 0 & 0 & 0 & 0 & 0 & 0 \\
\hline Consumer price index & 0 & 0 & 0 & 0 & 0 & 0 & 0 & 0 & 0 & 0 \\
\hline Real GDP growth rate & 0 & 0 & 0 & 0 & 0 & 0 & 0 & 0 & 0 & 0 \\
\hline Money market rate & -0.00041 & 0 & 0 & 0 & 0 & -0.00056 & 0 & 0 & 0 & 0 \\
\hline 3-month Treasury bill rate & 0 & 0 & 0 & 0 & 0 & 0 & 0 & 0 & 0 & 0 \\
\hline Bank deposit rate & 0 & 0 & 0 & 0 & 0 & 0 & 0 & 0 & 0 & 0 \\
\hline Bank lending rate & 0 & 0 & 0 & 0 & 0 & 0 & 0 & 0 & 0 & 0 \\
\hline 10-year Treasury bond yield & 0.000342 & 0.000222 & 0 & 0.000458 & 0 & 0.00023 & 0 & 0 & 0.000702 & 0 \\
\hline Unemployment rate & 0 & 0 & 0 & $-6.82 \mathrm{E}-05$ & 0 & 0 & 0 & 0 & $-3.20 \mathrm{E}-05$ & 0 \\
\hline U.S. real GDP growth rate & 0 & 0 & 0 & 0 & 0 & 0 & 0 & 0 & 0 & 0 \\
\hline People's Republic of China real growth rate & 0 & 0 & 0 & 0 & 0 & 0 & 0 & 0 & 0 & 0 \\
\hline U.S. policy rate & 0 & 0 & 0 & 0.000341 & 0 & 0 & 0 & 0 & 0.000713 & 0 \\
\hline Credit, growth rate & 0 & 0 & 0 & 0 & $2.45 \mathrm{E}-10$ & 0 & 0 & 0 & 0 & $3.39 \mathrm{E}-09$ \\
\hline U.S. consumer price index & 0 & 0 & 0 & 0 & $-6.35 E-07$ & 0 & 0 & 0 & 0 & $-1.13 \mathrm{E}-05$ \\
\hline Commodity price index & 0 & 0 & 0 & 0 & 0 & 0 & 0 & 0 & 0 & 0 \\
\hline Nominal effective exchange rate & 0 & 0 & 0 & 0 & 0 & 0 & 0 & 0 & 0 & 0 \\
\hline
\end{tabular}

\begin{tabular}{|c|c|c|c|c|c|c|c|c|c|c|}
\hline \multirow{4}{*}{ Variables } & \multicolumn{10}{|c|}{ Panel $\mathrm{H}$ : Industrials } \\
\hline & \multirow{2}{*}{\multicolumn{5}{|c|}{$\begin{array}{l}\text { Lasso } \\
\text { Number of lags }\end{array}$}} & \multirow{2}{*}{\multicolumn{5}{|c|}{$\begin{array}{l}\text { Relaxed Lasso } \\
\text { Number of lags }\end{array}$}} \\
\hline & & & & & & & & & & \\
\hline & 0 & 1 & 2 & 3 & 4 & 0 & 1 & 2 & 3 & 4 \\
\hline Exchange rate vis-à-vis the U.S. dollar & 0.000375 & 0 & 0 & 0.000577 & 0.000121 & 0.000581 & 0 & 0 & 0.001423 & 0.000611 \\
\hline Real effective exchange rate & 0 & $6.43 \mathrm{E}-05$ & 0.000131 & 4.38E-05 & $1.06 \mathrm{E}-05$ & 0 & 8.16E-05 & 0.000173 & 0.000154 & $6.74 \mathrm{E}-05$ \\
\hline Policy rate & -0.00033 & 0 & 0 & 0 & 0 & -0.0004 & 0 & 0 & 0 & 0 \\
\hline Consumer price index & 0 & 0 & 0 & 0 & 0 & 0 & 0 & 0 & 0 & 0 \\
\hline Real GDP growth rate & 0 & 0 & 0 & 0 & 0 & 0 & 0 & 0 & 0 & 0 \\
\hline Money market rate & 0 & 0 & 0 & 0 & 0 & 0 & 0 & 0 & 0 & 0 \\
\hline 3-month Treasury bill rate & 0 & 0 & 0 & 0 & 0 & 0 & 0 & 0 & 0 & 0 \\
\hline Bank deposit rate & 0 & 0.000629 & 0 & $9.79 \mathrm{E}-05$ & 0 & 0 & 0.000866 & 0 & $2.98 \mathrm{E}-05$ & 0 \\
\hline Bank lending rate & 0 & 0 & 0 & 0 & 0 & 0 & 0 & 0 & 0 & 0 \\
\hline 10-year Treasury bond yield & 0 & 0.000826 & 0 & 0 & 0.001232 & 0 & 0.001067 & 0 & 0 & 0.001071 \\
\hline Unemployment rate & 0.000342 & 0 & $-8.89 \mathrm{E}-05$ & 0 & -0.00015 & 0.000415 & 0 & $-5.09 E-05$ & 0 & -0.00021 \\
\hline U.S. real GDP growth rate & 0 & 0 & 0 & 0 & 0 & 0 & 0 & 0 & 0 & 0 \\
\hline People's Republic of China real growth rate & 0 & 0 & 0 & 0 & 0 & 0 & 0 & 0 & 0 & 0 \\
\hline U.S. policy rate & 0 & 0 & 0 & 0 & 7.60E-06 & 0 & 0 & 0 & 0 & 0.00028 \\
\hline Credit, growth rate & 0 & 0 & 0 & 0 & 0 & 0 & 0 & 0 & 0 & 0 \\
\hline U.S. consumer price index & $-4.60 \mathrm{E}-06$ & 0 & $6.60 \mathrm{E}-07$ & 0 & 8.04E-06 & $-8.49 E-06$ & 0 & $5.25 \mathrm{E}-07$ & 0 & $1.20 \mathrm{E}-05$ \\
\hline Commodity price index & 0 & 0 & 0 & 0 & 0 & 0 & 0 & 0 & 0 & 0 \\
\hline Nominal effective exchange rate & $-7.66 \mathrm{E}-05$ & 0 & 0 & 0 & 0 & $-4.77 \mathrm{E}-05$ & 0 & 0 & 0 & 0 \\
\hline
\end{tabular}

Source: Author's calculations. 
Table 1. Lasso and relaxed lasso, coefficient estimates, $\lambda$-mi specification (continued)

\begin{tabular}{|c|c|c|c|c|c|c|c|c|c|c|}
\hline \multirow{3}{*}{ Variables } & \multicolumn{10}{|c|}{ Panel I: Technology } \\
\hline & \multicolumn{5}{|c|}{$\begin{array}{l}\text { Lasso } \\
\text { Number of lags }\end{array}$} & \multicolumn{5}{|c|}{$\begin{array}{l}\text { Relaxed Lasso } \\
\text { Number of lags }\end{array}$} \\
\hline & 0 & 1 & 2 & 3 & 4 & 0 & 1 & 2 & 3 & 4 \\
\hline Exchange rate vis-à-vis the U.S. dollar & 0 & 0 & 0 & 0.000578 & 0 & 0 & 0 & 0 & 0.001326 & 0 \\
\hline Real effective exchange rate & 0 & $-7.14 \mathrm{E}-05$ & 0 & 0 & $-8.35 E-05$ & 0 & $-9.61 E-05$ & 0 & 0 & $-1.62 \mathrm{E}-05$ \\
\hline Policy rate & 0 & 0 & 0 & 0 & 0 & 0 & 0 & 0 & 0 & 0 \\
\hline Consumer price index & 0 & 0 & 0 & 0 & 0 & 0 & 0 & 0 & 0 & 0 \\
\hline Real GDP growth rate & 0 & 0 & 0 & 0 & 0 & 0 & 0 & 0 & 0 & 0 \\
\hline Money market rate & 0 & 0 & 0 & 0 & 0 & 0 & 0 & 0 & 0 & 0 \\
\hline 3-month Treasury bill rate & 0 & 0 & 0 & 0 & 0 & 0 & 0 & 0 & 0 & 0 \\
\hline Bank deposit rate & 0 & $3.91 \mathrm{E}-05$ & 0 & 0 & 0 & 0 & 0.000137 & 0 & 0 & 0 \\
\hline Bank lending rate & 0 & 0 & 0 & 0 & 0 & 0 & 0 & 0 & 0 & 0 \\
\hline 10-year Treasury bond yield & $6.48 \mathrm{E}-05$ & 0.000811 & 0.0001 & 0.000782 & 0.000269 & 0 & 0.000132 & 0 & 0.000585 & 0.000218 \\
\hline Unemployment rate & 7.02E-05 & 0 & 0 & 0 & 0 & 0.00028 & 0 & 0 & 0 & 0 \\
\hline U.S. real GDP growth rate & 0 & 0 & 0 & 0 & 0 & 0 & 0 & 0 & 0 & 0 \\
\hline People's Republic of China real growth rate & 0 & 0 & 0 & 0 & 0 & 0 & 0 & 0 & 0 & 0 \\
\hline U.S. policy rate & 0 & 0 & 0.000207 & 0 & 0 & 0 & 0 & 0.000436 & 0 & 0 \\
\hline Credit, growth rate & 0 & 0 & 0 & 0 & 0 & 0 & 0 & 0 & 0 & 0 \\
\hline U.S. consumer price index & $-5.51 \mathrm{E}-07$ & 0 & 0 & 0 & 0 & $-3.91 E-06$ & 0 & 0 & 0 & 0 \\
\hline Commodity price index & 0 & 0 & 0 & 0 & 0 & 0 & 0 & 0 & 0 & 0 \\
\hline Nominal effective exchange rate & 0 & 0 & 0 & 0 & 0 & 0 & 0 & 0 & 0 & 0 \\
\hline
\end{tabular}

\begin{tabular}{|c|c|c|c|c|c|c|c|c|c|c|}
\hline \multirow{4}{*}{ Variables } & \multicolumn{10}{|c|}{ Panel J: Utilities } \\
\hline & \multirow{2}{*}{\multicolumn{5}{|c|}{$\begin{array}{l}\text { Lasso } \\
\text { Number of lags }\end{array}$}} & \multirow{2}{*}{\multicolumn{5}{|c|}{$\begin{array}{l}\text { Relaxed Lasso } \\
\text { Number of lags }\end{array}$}} \\
\hline & & & & & & & & & & \\
\hline & 0 & 1 & 2 & 3 & 4 & 0 & 1 & 2 & 3 & 4 \\
\hline Exchange rate vis-à-vis the U.S. dollar & 0 & 0 & -0.00013 & 0 & -0.00013 & 0 & 0 & -0.00064 & 0 & -0.00045 \\
\hline Real effective exchange rate & -0.00054 & 0.000261 & 0 & 0 & $2.51 \mathrm{E}-05$ & -0.00062 & 0.000342 & 0 & 0 & 0 \\
\hline Policy rate & 0 & 0 & 0 & 0 & 0.001199 & 0 & 0 & 0 & 0 & 0.001559 \\
\hline Consumer price index & 0 & 0 & 0 & 0 & 0 & 0 & 0 & 0 & 0 & 0 \\
\hline Real GDP growth rate & 0 & 0 & 0 & 0 & 0 & 0 & 0 & 0 & 0 & 0 \\
\hline Money market rate & 0 & 0 & 0.001141 & 0 & 0 & 0 & 0 & 0.001146 & 0 & 0 \\
\hline 3-month Treasury bill rate & -0.00149 & 0 & 0 & 0 & 0 & -0.0011 & 0 & 0 & 0 & 0 \\
\hline Bank deposit rate & 0 & 0 & 0 & 0 & 0 & 0 & 0 & 0 & 0 & 0 \\
\hline Bank lending rate & 0 & 0 & 0 & 0 & 0 & 0 & 0 & 0 & 0 & 0 \\
\hline 10-year Treasury bond yield & 0 & 0.002135 & 0 & 0.000329 & -0.0003 & 0 & 0.002787 & 0 & 0.000222 & -0.00047 \\
\hline Unemployment rate & -0.00047 & 3.93E-05 & $-1.42 \mathrm{E}-05$ & 1.44E-05 & 0 & -0.00029 & 0.000242 & $-6.11 E-06$ & $-1.04 \mathrm{E}-05$ & 0 \\
\hline U.S. real GDP growth rate & 0 & 0 & 0 & 0 & 0 & 0 & 0 & 0 & 0 & 0 \\
\hline People's Republic of China real growth rate & 0 & 0 & 0 & 0 & 0 & 0 & 0 & 0 & 0 & 0 \\
\hline U.S. policy rate & 0.002103 & 0.000416 & 0 & 0 & -0.00343 & 0.003295 & 0 & 0 & 0 & -0.00399 \\
\hline Credit, growth rate & 0 & 0 & 0 & 0 & 0 & 0 & 0 & 0 & 0 & 0 \\
\hline U.S. consumer price index & 0 & $2.53 \mathrm{E}-05$ & 0 & $6.60 \mathrm{E}-06$ & $1.62 \mathrm{E}-05$ & 0 & $2.41 \mathrm{E}-05$ & 0 & 7.26E-06 & 2.47E-05 \\
\hline Commodity price index & 0 & 0 & 0 & 0 & 0 & 0 & 0 & 0 & 0 & 0 \\
\hline Nominal effective exchange rate & 0 & 0 & $1.02 \mathrm{E}-05$ & 0 & 0 & 0 & 0 & 0 & 0 & 0 \\
\hline
\end{tabular}

Source: Author's calculations. 
Table 2 . Lasso and relaxed lasso, coefficient estimates, $\lambda$-1se specification

\begin{tabular}{|c|c|c|c|c|c|c|c|c|c|c|}
\hline \multirow{4}{*}{ Variables } & \multicolumn{10}{|c|}{ Panel A: Basic Materials } \\
\hline & \multirow{2}{*}{\multicolumn{5}{|c|}{$\begin{array}{c}\text { Lasso } \\
\text { Number of lags }\end{array}$}} & \multirow{2}{*}{\multicolumn{5}{|c|}{$\begin{array}{l}\text { Relaxed Lasso } \\
\text { Number of lags }\end{array}$}} \\
\hline & & & & & & & & & & \\
\hline & 0 & 1 & 2 & 3 & 4 & 0 & 1 & 2 & 3 & 4 \\
\hline Exchange rate vis-à-vis the U.S. dollar & 0 & 0 & 0 & 0 & 0 & 0 & 0 & 0 & 0 & 0 \\
\hline Real effective exchange rate & 0 & 0 & 0 & 0 & 0 & 0 & 0 & 0 & 0 & 0 \\
\hline Policy rate & 0 & 0 & 0 & 0 & 0 & 0 & 0 & 0 & 0 & 0 \\
\hline Consumer price index & 0 & 0 & 0 & 0 & 0 & 0 & 0 & 0 & 0 & 0 \\
\hline Real GDP growth rate & 0 & 0 & 0 & 0 & 0 & 0 & 0 & 0 & 0 & 0 \\
\hline Money market rate & 0 & 0 & 0 & 0 & 0 & 0 & 0 & 0 & 0 & 0 \\
\hline 3-month Treasury bill rate & 0 & 0 & 0 & 0 & 0 & 0 & 0 & 0 & 0 & 0 \\
\hline Bank deposit rate & 0 & 0 & 0 & 0 & 0 & 0 & 0 & 0 & 0 & 0 \\
\hline Bank lending rate & 0 & 0 & 0 & 0 & 0 & 0 & 0 & 0 & 0 & 0 \\
\hline 10-year Treasury bond yield & 0 & 0 & 0 & 0 & 0 & 0 & 0 & 0 & 0 & 0 \\
\hline Unemployment rate & 0 & 0 & 0 & 0 & 0 & 0 & 0 & 0 & 0 & 0 \\
\hline U.S. real GDP growth rate & 0 & 0 & 0 & 0 & 0 & 0 & 0 & 0 & 0 & 0 \\
\hline People's Republic of China real growth rate & 0 & 0 & 0 & 0 & 0 & 0 & 0 & 0 & 0 & 0 \\
\hline U.S. policy rate & 0 & 0 & 0 & 0 & 0 & 0 & 0 & 0 & 0 & 0 \\
\hline Credit, growth rate & 0 & 0 & 0 & 0 & 0 & 0 & 0 & 0 & 0 & 0 \\
\hline U.S. consumer price index & 0 & 0 & 0 & 0 & 0 & 0 & 0 & 0 & 0 & 0 \\
\hline Commodity price index & 0 & 0 & 0 & 0 & 0 & 0 & 0 & 0 & 0 & 0 \\
\hline Nominal effective exchange rate & 0 & 0 & 0 & 0 & 0 & 0 & 0 & 0 & 0 & 0 \\
\hline
\end{tabular}

\begin{tabular}{|c|c|c|c|c|c|c|c|c|c|c|}
\hline \multirow{3}{*}{ Variables } & \multicolumn{10}{|c|}{ Panel B: Communications } \\
\hline & \multicolumn{5}{|c|}{$\begin{array}{c}\text { Lasso } \\
\text { Number of lags }\end{array}$} & \multicolumn{5}{|c|}{$\begin{array}{l}\text { Relaxed Lasso } \\
\text { Number of lags }\end{array}$} \\
\hline & 0 & 1 & 2 & 3 & 4 & 0 & 1 & 2 & 3 & 4 \\
\hline Exchange rate vis-à-vis the U.S. dollar & 0.00189 & 0 & 0 & 0 & 0 & 0.001015 & 0 & 0 & 0.00034 & 0 \\
\hline Real effective exchange rate & $-2.3 \mathrm{E}-05$ & 0 & 3.11E-05 & 0 & 0 & -0.00015 & 0 & 0.000201 & 0 & 0 \\
\hline Policy rate & 0 & 0 & 0 & 0 & 0 & -0.00151 & -0.00059 & 0 & 0 & 0 \\
\hline Consumer price index & 0 & 0 & 0 & 0 & 0 & 0 & 0 & 0 & 0 & 0 \\
\hline Real GDP growth rate & 0 & 0 & 0 & 0 & 0 & 0 & 0 & 0 & 0 & 0 \\
\hline Money market rate & -0.00119 & $-7.1 \mathrm{E}-05$ & 0 & 0 & 0 & 0 & 0 & 0 & 0 & 0 \\
\hline 3-month Treasury bill rate & 0 & 0 & 0 & 0 & 0 & 0 & 0 & 0 & 0 & 0 \\
\hline Bank deposit rate & 0 & 0 & 0 & 0 & 0 & 0 & 0 & 0 & 0 & 0 \\
\hline Bank lending rate & 0 & 0 & 0 & 0 & 0 & 0 & 0 & 0 & 0 & 0 \\
\hline 10-year Treasury bond yield & 0.000688 & 0 & 0.000136 & 0.000692 & 0.002436 & 0.001108 & 0 & 0.001038 & 0.000734 & 0.001946 \\
\hline Unemployment rate & 0.000371 & 0 & 0 & -0.00061 & -0.00029 & 0.000689 & 0.000377 & 0 & -0.00046 & -0.0006 \\
\hline U.S. real GDP growth rate & 0 & 0 & 0 & 0 & 0 & 0 & 0 & 0 & 0 & 0 \\
\hline People's Republic of China real growth rate & 0 & 0 & 0 & 0 & 0 & 0 & 0 & 0 & 0 & 0 \\
\hline U.S. policy rate & 0 & 0 & 0 & 0 & 0.001182 & 0 & 0 & 0 & 0 & 0.002319 \\
\hline Credit, growth rate & 0 & 0 & 0 & 0 & 0 & 0 & 0 & 0 & 0 & 0 \\
\hline U.S. consumer price index & 0 & 0 & 0 & 0 & 0 & 0 & 0 & 0 & 0 & 0 \\
\hline Commodity price index & 0 & 0 & 0 & 0 & 0 & 0 & 0 & 0 & 0 & 0 \\
\hline Nominal effective exchange rate & 0 & 0 & 8.57E-05 & 0 & 0 & 0 & 0 & $9.24 \mathrm{E}-07$ & 0 & 0 \\
\hline
\end{tabular}

Source: Author's calculations. 
Table 2. Lasso and relaxed lasso, coefficient estimates, $\lambda$-1se specification (continued)

\begin{tabular}{|c|c|c|c|c|c|c|c|c|c|c|}
\hline \multirow{3}{*}{ Variables } & \multicolumn{10}{|c|}{ Panel C: Consumer Cyclicals } \\
\hline & \multicolumn{5}{|c|}{$\begin{array}{c}\text { Lasso } \\
\text { Number of lags }\end{array}$} & \multicolumn{5}{|c|}{$\begin{array}{l}\text { Relaxed Lasso } \\
\text { Number of lags }\end{array}$} \\
\hline & 0 & 1 & 2 & 3 & 4 & 0 & 1 & 2 & 3 & 4 \\
\hline Exchange rate vis-à-vis the U.S. dollar & 0.000593 & 0 & 0 & 0 & 0 & 0.000656 & 0 & 0 & 0 & 0 \\
\hline Real effective exchange rate & 0 & 0 & 0 & 0 & 0 & 0 & 0 & 0 & 0 & 0 \\
\hline Policy rate & 0 & 0 & 0 & 0 & 0 & 0 & 0 & 0 & 0 & 0 \\
\hline Consumer price index & 0 & 0 & 0 & 0 & 0 & 0 & 0 & 0 & 0 & 0 \\
\hline Real GDP growth rate & 0 & 0 & 0 & 0 & 0 & 0 & 0 & 0 & 0 & 0 \\
\hline Money market rate & 0 & 0 & 0 & 0 & 0 & -0.00011 & 0 & 0 & 0 & 0 \\
\hline 3-month Treasury bill rate & 0 & 0 & 0 & 0 & 0 & 0 & 0 & 0 & 0 & 0 \\
\hline Bank deposit rate & 0 & 0 & 0 & 0 & 0 & 0 & 0 & 0 & 0 & 0 \\
\hline Bank lending rate & 0 & 0 & 0 & 0 & 0 & 0 & 0 & 0 & 0 & 0 \\
\hline 10-year Treasury bond yield & 0 & 0.000646 & 0.000399 & $2.22 \mathrm{E}-04$ & 0.000882 & 3.74E-05 & 0.00077 & 0.00048 & 2.12E-04 & 0.001011 \\
\hline Unemployment rate & 0 & 0 & $-1.08 \mathrm{E}-05$ & -0.0002 & -0.00011 & 0 & $0.00 \mathrm{E}+00$ & $-1.24 \mathrm{E}-04$ & -0.00021 & -0.00018 \\
\hline U.S. real GDP growth rate & 0 & 0 & 0 & 0 & 0 & 0 & 0 & 0 & 0 & 0 \\
\hline People's Republic of China real growth rate & 0 & 0 & 0 & 0 & 0 & 0 & 0 & 0 & 0 & 0 \\
\hline U.S. policy rate & 0 & 0 & 0 & 0 & 0 & 0 & 0 & 0 & 0 & 0 \\
\hline Credit, growth rate & 0 & 0 & 0 & 0 & 0 & 0 & 0 & 0 & 0 & 0 \\
\hline U.S. consumer price index & 0 & 0 & 0 & 0 & 0 & 0 & 0 & 0 & 0 & 2.94E-07 \\
\hline Commodity price index & 0 & 0 & 0 & 0 & 0 & 0 & 0 & 0 & 0 & 0 \\
\hline Nominal effective exchange rate & 0 & 0 & 0 & 0 & 0 & 0 & 0 & 0 & 0 & 0 \\
\hline
\end{tabular}

\begin{tabular}{|c|c|c|c|c|c|c|c|c|c|c|}
\hline \multirow{3}{*}{ Variables } & \multicolumn{10}{|c|}{ Panel D: Consumer non-Cyclicals } \\
\hline & \multicolumn{5}{|c|}{$\begin{array}{l}\text { Lasso } \\
\text { Number of lags }\end{array}$} & \multicolumn{5}{|c|}{$\begin{array}{l}\text { Relaxed Lasso } \\
\text { Number of lags }\end{array}$} \\
\hline & 0 & 1 & 2 & 3 & 4 & 0 & 1 & 2 & 3 & 4 \\
\hline Exchange rate vis-à-vis the U.S. dollar & 0.000888 & 0 & 0 & 0 & 0.000673 & 0.000935 & 0 & 0 & 0 & 0.00089 \\
\hline Real effective exchange rate & 0 & 0 & 0 & 0 & 0 & 0 & 0 & 4.24E-05 & 0 & 0 \\
\hline Policy rate & 0 & 0 & 0 & 0 & 0 & 0 & 0 & 0 & 0 & 0 \\
\hline Consumer price index & 0 & 0 & 0 & 0 & 0 & 0 & 0 & 0 & 0 & 0 \\
\hline Real GDP growth rate & 0 & 0 & 0 & 0 & 0 & 0 & 0 & 0 & 0 & 0 \\
\hline Money market rate & 0 & 0 & 0 & 0 & 0 & 0 & 0 & 0 & 0 & 0 \\
\hline 3-month Treasury bill rate & 0 & 0 & 0 & 0 & 0 & 0 & 0 & 0 & 0 & 0 \\
\hline Bank deposit rate & 0 & 0 & 0 & 0 & 0 & 0 & 0 & 0 & 0 & 0 \\
\hline Bank lending rate & 0 & 0 & 0 & 0 & 0 & 0 & 0 & 0 & 0 & 0 \\
\hline 10-year Treasury bond yield & 0.000306 & $8.66 \mathrm{E}-05$ & $3.42 \mathrm{E}-05$ & 0.000752 & 0.001299 & 0.000234 & 0.000313 & 0 & 0.000694 & 0.001269 \\
\hline Unemployment rate & 0.000213 & 0 & 0 & -0.00034 & $-5.75 E-05$ & 0.000343 & 0 & 0 & -0.00037 & -0.00014 \\
\hline U.S. real GDP growth rate & 0 & 0 & 0 & 0 & 0 & 0 & 0 & 0 & 0 & 0 \\
\hline People's Republic of China real growth rate & 0 & 0 & 0 & 0 & 0 & 0 & 0 & 0 & 0 & 0 \\
\hline U.S. policy rate & 0 & 0 & 0 & 0.000264 & 0 & 0 & 0 & 4.01E-05 & 0.000338 & 0 \\
\hline Credit, growth rate & 0 & 0 & 0 & 0 & 0 & 0 & 0 & 0 & 0 & 0 \\
\hline U.S. consumer price index & 0 & 0 & 0 & 0 & $-1.30 \mathrm{E}-06$ & $-1.24 \mathrm{E}-06$ & 0 & 0 & 0 & 0 \\
\hline Commodity price index & 0 & 0 & 0 & 0 & 0 & 0 & 0 & 0 & 0 & 0 \\
\hline Nominal effective exchange rate & 0 & 0 & 0 & 0 & 0 & 0 & 0 & 0 & 0 & 0 \\
\hline
\end{tabular}

Source: Author's calculations. 
Table 2. Lasso and relaxed lasso, coefficient estimates, $\lambda$-1se specification (continued)

\begin{tabular}{|c|c|c|c|c|c|c|c|c|c|c|}
\hline \multirow{3}{*}{ Variables } & \multicolumn{10}{|c|}{ Panel E: Diversified Industrials } \\
\hline & \multicolumn{5}{|c|}{$\begin{array}{c}\text { Lasso } \\
\text { Number of lags }\end{array}$} & \multicolumn{5}{|c|}{$\begin{array}{l}\text { Relaxed Lasso } \\
\text { Number of lags }\end{array}$} \\
\hline & 0 & 1 & 2 & 3 & 4 & 0 & 1 & 2 & 3 & 4 \\
\hline Exchange rate vis-à-vis the U.S. dollar & 0 & 0 & 0 & 0 & 0 & 0 & 0 & 0 & 0 & 0 \\
\hline Real effective exchange rate & 0 & 0 & 0 & 0 & 0 & 0 & 0 & 0 & 0 & 0 \\
\hline Policy rate & 0 & 0 & 0 & 0 & 0 & 0 & 0 & 0 & 0 & 0 \\
\hline Consumer price index & 0 & 0 & 0 & 0 & 0 & 0 & 0 & 0 & 0 & 0 \\
\hline Real GDP growth rate & 0 & 0 & 0 & 0 & 0 & 0 & 0 & 0 & 0 & 0 \\
\hline Money market rate & 0 & 0 & 0 & 0 & 0 & 0 & 0 & 0 & 0 & 0 \\
\hline 3-month Treasury bill rate & 0 & 0 & 0 & 0 & 0 & 0 & 0 & 0 & 0 & 0 \\
\hline Bank deposit rate & 0 & 0 & 0 & 0 & 0 & 0 & 4.84E-05 & 0 & 0 & 0 \\
\hline Bank lending rate & 0 & 0 & 0 & 0 & 0 & 0 & 0 & 0 & 0 & 0 \\
\hline 10-year Treasury bond yield & 0 & 0 & 0 & 0 & 0 & 0.000354 & 0.000632 & 0 & 0 & 0 \\
\hline Unemployment rate & 0 & 0 & 0 & 0 & 0 & 0 & 0 & 0 & 0 & 0 \\
\hline U.S. real GDP growth rate & 0 & 0 & 0 & 0 & 0 & 0 & 0 & 0 & 0 & 0 \\
\hline People's Republic of China real growth rate & 0 & 0 & 0 & 0 & 0 & 0 & 0 & 0 & 0 & 0 \\
\hline U.S. policy rate & 0 & 0 & 0 & 0 & 0 & 0 & 0 & 0 & 0 & 0 \\
\hline Credit, growth rate & 0 & 0 & 0 & 0 & 0 & 0 & 0 & 0 & 0 & 0 \\
\hline U.S. consumer price index & 0 & 0 & 0 & 0 & 0 & 0 & $4.42 \mathrm{E}-06$ & 0 & 0 & 0 \\
\hline Commodity price index & 0 & 0 & 0 & 0 & 0 & 0 & 0 & 0 & 0 & 0 \\
\hline Nominal effective exchange rate & 0 & 0 & 0 & 0 & 0 & 0 & 0 & 0 & 0 & 0 \\
\hline
\end{tabular}

\begin{tabular}{|c|c|c|c|c|c|c|c|c|c|c|}
\hline \multirow{3}{*}{ Variables } & \multicolumn{10}{|c|}{ Panel F: Energy } \\
\hline & \multicolumn{5}{|c|}{$\begin{array}{c}\text { Lasso } \\
\text { Number of lags }\end{array}$} & \multicolumn{5}{|c|}{$\begin{array}{l}\text { Relaxed Lasso } \\
\text { Number of lags }\end{array}$} \\
\hline & 0 & 1 & 2 & 3 & 4 & 0 & 1 & 2 & 3 & 4 \\
\hline Exchange rate vis-à-vis the U.S. dollar & 0 & 0 & 0 & 0 & 0 & 0 & 0 & 0 & 0 & 0 \\
\hline Real effective exchange rate & 0 & 0 & 0 & 0 & 0 & 0 & 0 & 0 & 0 & 0 \\
\hline Policy rate & 0 & 0 & 0 & 0 & 0 & 0 & 0 & 0 & 0 & 0 \\
\hline Consumer price index & 0 & 0 & 0 & 0 & 0 & 0 & 0 & 0 & 0 & 0 \\
\hline Real GDP growth rate & 0 & 0 & 0 & 0 & 0 & 0 & 0 & 0 & 0 & 0 \\
\hline Money market rate & 0 & 0 & 0 & 0 & 0 & 0 & 0 & 0 & 0 & 0 \\
\hline 3-month Treasury bill rate & 0 & 0 & 0 & 0 & 0 & 0 & 0 & 0 & 0 & 0 \\
\hline Bank deposit rate & 0 & 0 & 0 & 0 & 0 & 0 & 0 & 0 & 0 & 0 \\
\hline Bank lending rate & 0 & 0 & 0 & 0 & 0 & 0 & 0 & 0 & 0 & 0 \\
\hline 10-year Treasury bond yield & 0 & 0 & 0 & 0 & 0.002238 & 0 & 0 & 0 & 0 & 0 \\
\hline Unemployment rate & 0 & 0 & 0 & 0 & 0 & 0 & 0 & 0 & 0 & 0 \\
\hline U.S. real GDP growth rate & 0 & 0 & 0 & 0 & 0 & 0 & 0 & 0 & 0 & 0 \\
\hline People's Republic of China real growth rate & 0 & 0 & 0 & 0 & 0 & 0 & 0 & 0 & 0 & 0 \\
\hline U.S. policy rate & 0 & 0 & 0 & 0 & 0 & 0 & 0 & 0 & 0 & 0 \\
\hline Credit, growth rate & 0 & 0 & 0 & 0 & 0 & 0 & 0 & 0 & 0 & 0 \\
\hline U.S. consumer price index & 0 & 0 & 0 & 0 & 0 & 0 & 0 & 0 & 0 & 0 \\
\hline Commodity price index & 0 & 0 & 0 & 0 & 0 & 0 & 0 & 0 & 0 & 0 \\
\hline Nominal effective exchange rate & 0 & 0 & 0 & 0 & 0 & 0 & 0 & 0 & 0 & 0 \\
\hline
\end{tabular}

Source: Author's calculations. 
Table 2. Lasso and relaxed lasso, coefficient estimates, $\lambda$-1se specification (continued)

\begin{tabular}{|c|c|c|c|c|c|c|c|c|c|c|}
\hline \multirow{3}{*}{ Variables } & \multicolumn{10}{|c|}{ Panel G: Financials } \\
\hline & \multicolumn{5}{|c|}{$\begin{array}{c}\text { Lasso } \\
\text { Number of lags }\end{array}$} & \multicolumn{5}{|c|}{$\begin{array}{l}\text { Relaxed Lasso } \\
\text { Number of lags }\end{array}$} \\
\hline & 0 & 1 & 2 & 3 & 4 & 0 & 1 & 2 & 3 & 4 \\
\hline Exchange rate vis-à-vis the U.S. dollar & 0.001016 & 0.000606 & $2.82 \mathrm{E}-05$ & 0 & 0.000184 & 0.001282 & 0.00042 & $7.22 \mathrm{E}-05$ & 0 & 0.000325 \\
\hline Real effective exchange rate & 0 & 0 & 0 & 0 & 0 & 0 & 0 & 0 & 0 & 0 \\
\hline Policy rate & 0 & 0 & 0 & 0 & 0 & 0 & 0 & 0 & 0 & 0 \\
\hline Consumer price index & 0 & 0 & 0 & 0 & 0 & 0 & 0 & 0 & 0 & 0 \\
\hline Real GDP growth rate & 0 & 0 & 0 & 0 & 0 & 0 & 0 & 0 & 0 & 0 \\
\hline Money market rate & 0 & 0 & 0 & 0 & 0 & 0 & 0 & 0 & 0 & 0 \\
\hline 3-month Treasury bill rate & 0 & 0 & 0 & 0 & 0 & 0 & 0 & 0 & 0 & 0 \\
\hline Bank deposit rate & 0 & 0 & 0 & 0 & 0 & 0 & 0 & 0 & 0 & 0 \\
\hline Bank lending rate & 0 & 0 & 0 & 0 & 0 & 0 & 0 & 0 & 0 & 0 \\
\hline 10-year Treasury bond yield & 0.000349 & 0 & 0 & 0.000145 & 0 & 0.000386 & 0 & 0 & 0.000288 & 0 \\
\hline Unemployment rate & 0 & 0 & 0 & 0 & 0 & 0 & 0 & 0 & 0 & 0 \\
\hline U.S. real GDP growth rate & 0 & 0 & 0 & 0 & 0 & 0 & 0 & 0 & 0 & 0 \\
\hline People's Republic of China real growth rate & 0 & 0 & 0 & 0 & 0 & 0 & 0 & 0 & 0 & 0 \\
\hline U.S. policy rate & 0 & 0 & 0 & 0 & 0 & 0 & 0 & 0 & 0 & 0 \\
\hline Credit, growth rate & 0 & 0 & 0 & 0 & 0 & 0 & 0 & 0 & 0 & 0 \\
\hline U.S. consumer price index & 0 & 0 & 0 & 0 & 0 & 0 & 0 & 0 & 0 & 0 \\
\hline Commodity price index & 0 & 0 & 0 & 0 & 0 & 0 & 0 & 0 & 0 & 0 \\
\hline Nominal effective exchange rate & 0 & 0 & 0 & 0 & 0 & 0 & 0 & 0 & 0 & 0 \\
\hline
\end{tabular}

\begin{tabular}{|c|c|c|c|c|c|c|c|c|c|c|}
\hline \multirow{3}{*}{ Variables } & \multicolumn{10}{|c|}{ Panel H: Industrials } \\
\hline & \multicolumn{5}{|c|}{$\begin{array}{l}\text { Lasso } \\
\text { Number of lags }\end{array}$} & \multicolumn{5}{|c|}{$\begin{array}{l}\text { Relaxed Lasso } \\
\text { Number of lags }\end{array}$} \\
\hline & 0 & 1 & 2 & $\begin{array}{ll}\text { gs } \\
3\end{array}$ & 4 & 0 & 1 & & $g s$ & 4 \\
\hline Exchange rate vis-à-vis the U.S. dollar & 0.000352 & 0 & 0 & 0.000226 & 0 & 0.000252 & 0 & 0 & 0.000249 & 3.19E-05 \\
\hline Real effective exchange rate & 0 & 4.73E-05 & 8.34E-05 & 0 & 0 & 0 & $5.38 \mathrm{E}-05$ & 0.000107 & 0 & 0 \\
\hline Policy rate & -0.0003 & 0 & 0 & 0 & 0 & -0.00034 & 0 & 0 & 0 & 0 \\
\hline Consumer price index & 0 & 0 & 0 & 0 & 0 & 0 & 0 & 0 & 0 & 0 \\
\hline Real GDP growth rate & 0 & 0 & 0 & 0 & 0 & 0 & 0 & 0 & 0 & 0 \\
\hline Money market rate & 0 & 0 & 0 & 0 & 0 & 0 & 0 & 0 & 0 & 0 \\
\hline 3-month Treasury bill rate & 0 & 0 & 0 & 0 & 0 & 0 & 0 & 0 & 0 & 0 \\
\hline Bank deposit rate & 0 & 0.00039 & 0 & 0.000215 & 0 & 0 & 0.000491 & 0 & 0.000157 & 0 \\
\hline Bank lending rate & 0 & 0 & 0 & 0 & 0 & 0 & 0 & 0 & 0 & 0 \\
\hline 10-year Treasury bond yield & 0 & 0.000607 & 0 & 0 & 0.001315 & 0 & 0.000733 & 0 & 0 & 0.001269 \\
\hline Unemployment rate & 0.00026 & 0 & -0.00012 & 0 & $-7.23 E-05$ & 0.000311 & 0 & $-8.41 \mathrm{E}-05$ & 0 & -0.00011 \\
\hline U.S. real GDP growth rate & 0 & 0 & 0 & 0 & 0 & 0 & 0 & 0 & 0 & 0 \\
\hline People's Republic of China real growth rate & 0 & 0 & 0 & 0 & 0 & 0 & 0 & 0 & 0 & 0 \\
\hline U.S. policy rate & 0 & $-5.68 \mathrm{E}-05$ & 0 & 0 & 0 & 0 & 0 & 0 & 0 & 0 \\
\hline Credit, growth rate & 0 & 0 & 0 & 0 & 0 & 0 & 0 & 0 & 0 & 0 \\
\hline U.S. consumer price index & $-1.81 \mathrm{E}-06$ & 0 & $1.74 \mathrm{E}-06$ & 0 & 5.07E-06 & $-2.95 \mathrm{E}-06$ & 0 & $1.12 \mathrm{E}-06$ & 0 & $6.35 \mathrm{E}-06$ \\
\hline Commodity price index & 0 & 0 & 0 & 0 & 0 & 0 & 0 & 0 & 0 & 0 \\
\hline Nominal effective exchange rate & $-6.51 E-05$ & 0 & 0 & 0 & 0 & $-8.63 \mathrm{E}-05$ & 0 & 0 & 0 & 0 \\
\hline
\end{tabular}

Source: Author's calculations. 
Table 2. Lasso and relaxed lasso, coefficient estimates, $\lambda$-1se specification (continued)

\begin{tabular}{|c|c|c|c|c|c|c|c|c|c|c|}
\hline \multirow{3}{*}{ Variables } & \multicolumn{10}{|c|}{ Panel I: Technology } \\
\hline & \multicolumn{5}{|c|}{$\begin{array}{c}\text { Lasso } \\
\text { Number of lags }\end{array}$} & \multicolumn{5}{|c|}{$\begin{array}{l}\text { Relaxed Lasso } \\
\text { Number of lags }\end{array}$} \\
\hline & 0 & 1 & 2 & 3 & 4 & 0 & 1 & 2 & 3 & 4 \\
\hline Exchange rate vis-à-vis the U.S. dollar & 0 & 0 & 0 & 0 & 0 & 0 & 0 & 0 & 0 & 0 \\
\hline Real effective exchange rate & 0 & $-3.80 \mathrm{E}-05$ & 0 & $-5.92 \mathrm{E}-05$ & $-6.37 \mathrm{E}-05$ & 0 & $-9.14 \mathrm{E}-05$ & 0 & 0 & $-9.20 \mathrm{E}-05$ \\
\hline Policy rate & 0 & 0 & 0 & 0 & 0 & 0 & 0 & 0 & 0 & 0 \\
\hline Consumer price index & 0 & 0 & 0 & 0 & 0 & 0 & 0 & 0 & 0 & 0 \\
\hline Real GDP growth rate & 0 & 0 & 0 & 0 & 0 & 0 & 0 & 0 & 0 & 0 \\
\hline Money market rate & 0 & 0 & 0 & 0 & 0 & 0 & 0 & 0 & 0 & 0 \\
\hline 3-month Treasury bill rate & 0 & 0 & 0 & 0 & 0 & 0 & 0 & 0 & 0 & 0 \\
\hline Bank deposit rate & 0 & 0 & 0 & 0 & 0 & 0 & 0 & 0 & 0 & 0 \\
\hline Bank lending rate & 0 & 0 & 0 & 0 & 0 & 0 & 0 & 0 & 0 & 0 \\
\hline 10-year Treasury bond yield & 0.000213 & 0.000734 & 0 & 0.000855 & 0.000103 & 0 & 0 & 0 & 0.000603 & 0 \\
\hline Unemployment rate & 0 & 0 & 0 & 0 & 0 & 4.22E-05 & 0 & 0 & 0 & 0 \\
\hline U.S. real GDP growth rate & 0 & 0 & 0 & 0 & 0 & 0 & 0 & 0 & 0 & 0 \\
\hline People's Republic of China real growth rate & 0 & 0 & 0 & 0 & 0 & 0 & 0 & 0 & 0 & 0 \\
\hline U.S. policy rate & 0 & 0 & 0 & 0 & 0 & 0 & 0 & 0 & 0 & 0 \\
\hline Credit, growth rate & 0 & 0 & 0 & 0 & 0 & 0 & 0 & 0 & 0 & 0 \\
\hline U.S. consumer price index & 0 & 0 & 0 & 0 & 0 & $-3.31 E-06$ & 0 & 0 & 0 & 0 \\
\hline Commodity price index & 0 & 0 & 0 & 0 & 0 & 0 & 0 & 0 & 0 & 0 \\
\hline Nominal effective exchange rate & 0 & 0 & 0 & 0 & 0 & 0 & 0 & 0 & 0 & 0 \\
\hline
\end{tabular}

\begin{tabular}{|c|c|c|c|c|c|c|c|c|c|c|}
\hline \multirow{3}{*}{ Variables } & \multicolumn{10}{|c|}{ Panel J: Utilities } \\
\hline & \multicolumn{5}{|c|}{$\begin{array}{c}\text { Lasso } \\
\text { Number of lags }\end{array}$} & \multicolumn{5}{|c|}{$\begin{array}{l}\text { Relaxed Lasso } \\
\text { Number of lags }\end{array}$} \\
\hline & 0 & 1 & 2 & 3 & 4 & 0 & 1 & 2 & 3 & 4 \\
\hline Exchange rate vis-à-vis the U.S. dollar & 0 & 0 & 0 & 0 & 0 & 0 & 0 & -0.00051 & 0 & -0.00073 \\
\hline Real effective exchange rate & 0 & 7.31E-06 & 0 & 0 & 0 & -0.00053 & 0.000303 & 0 & 0 & 0 \\
\hline Policy rate & 0 & 0 & 0 & 0 & 0 & 0 & 0 & 0 & 0 & 0.001369 \\
\hline Consumer price index & 0 & 0 & 0 & $2.52 \mathrm{E}-05$ & 0 & 0 & 0 & 0 & 0 & 0 \\
\hline Real GDP growth rate & 0 & 0 & 0 & 0 & 0 & 0 & 0 & 0 & 0 & 0 \\
\hline Money market rate & 0 & 0 & 0 & 0 & 0.000208 & 0 & 0 & 0.00106 & 0 & 0 \\
\hline 3-month Treasury bill rate & 0 & 0 & 0 & 0 & 0 & -0.00077 & 0 & 0 & 0 & 0 \\
\hline Bank deposit rate & 0 & 0 & 0 & 0 & 0 & 0 & 0 & 0 & 0 & 0 \\
\hline Bank lending rate & 0 & 0 & 0 & 0 & 0 & 0 & 0 & 0 & 0 & 0 \\
\hline 10-year Treasury bond yield & 0 & 0 & 0 & 0 & 0 & 0 & 0.002303 & 0 & 0 & 0 \\
\hline Unemployment rate & -0.0003 & 0 & 0 & 0 & 0 & -0.00036 & $6.54 \mathrm{E}-05$ & 0 & 0 & 0 \\
\hline U.S. real GDP growth rate & 0 & 0 & 0 & 0 & 0 & 0 & 0 & 0 & 0 & 0 \\
\hline People's Republic of China real growth rate & 0 & 0 & 0 & 0 & 0 & 0 & 0 & 0 & 0 & 0 \\
\hline U.S. policy rate & 0 & 0 & 0 & 0 & 0 & 0.002707 & 0 & 0 & 0 & -0.00359 \\
\hline Credit, growth rate & 0 & 0 & 0 & 0 & 0 & 0 & 0 & 0 & 0 & 0 \\
\hline U.S. consumer price index & 0 & 0 & $6.39 \mathrm{E}-06$ & 0 & $9.22 \mathrm{E}-06$ & 0 & $2.11 \mathrm{E}-05$ & 0 & $6.54 \mathrm{E}-06$ & 2.13E-05 \\
\hline Commodity price index & 0 & 0 & 0 & 0 & 0 & 0 & 0 & 0 & 0 & 0 \\
\hline Nominal effective exchange rate & 0 & 0 & 0 & 0 & 0 & 0 & 0 & 0 & 0 & 0 \\
\hline
\end{tabular}

Source: Author's calculations. 


\section{Conclusions}

Lasso regressions are likely to outperform traditional statistical models such as ordinary least squares in forecasting the performance indicators required in applied stress testing. The advantage of Lasso-type estimators lies in the fact that they can handle the complications arising from the high dimensional nature of stress tests.

Typically, the stress test specifies a large set of primary explanatory variables for which there are only few observations. This leads to a situation where the number of variables is of the same order of magnitude as the observations. Without regularizing (or shrinking) the coefficients, statistical models would be very unstable. In contrast, regularization methods, like Lasso, are designed specifically to handle high dimensional problems, many of which present in different areas of finance and economics, including financial networks.

Lasso-type estimators can also accommodate models other than the linear models described here. It is possible to use Lasso estimators in generalized linear models, including logistic regression, multiclass logistic regression, Cox proportional hazard models, and support vector machines; in semiparametric nonlinear mixed effect models (Arribas-Gil, Bertin, Meza, and Rivoirard, 2014), and nonlinear regressions (Tateishi, Matsui, and Konishi, 2010).

Economists may have some concerns with the "black box" nature of the variable selection process in Lasso-based methods. For instance, the resulting model may show coefficients with the "wrong signs" and at odds with the causality direction assumed by the analyst. The Lasso estimation framework can accommodate this situation easily since it can specify both upper bounds and lower bounds for the coefficient. It is also feasible to specify linear restrictions on the coefficient (James, Paulson, and Rusmevichientong, 2013).

There may be concerns associated with whether the right variables are included in the model. Given the large number of covariates, the Lasso estimator may choose some variables highly collinear with the "right" set of variables if they have a better signal-to-noise ratio. This situation may complicate the association of the stress test outcomes with economic narratives. But because stress tests are quantitative tools, it may be more important to obtain good out-of-sample forecasts rather than telling a good story. Progress towards standardizing and automating stress test scenarios may reduce the importance of an economic narrative.

The availability of fast computation algorithms for estimating Lasso-type regressions in major programming and statistical languages, including Matlab, R, and SAS, suggest their usefulness as basic building blocks in practical semi- or fully automated stress testing platforms. Chan-Lau and Li (2015) describe one such platform combining Lasso-based forecasting models with a balance sheet stress test model. This type of stress test platforms could analyze multiple stress scenarios efficiently and rapidly within an enterprise-wide risk framework in a private firm, or in a systemic risk framework in a regulatory agency. 


\section{References}

Barigozzi, M. and C. Brownless, 2014, "NETS: Network Estimation for Time Series," mimeo (London School of Economics and Universitat Pompeu Fabra).

Arribas-Gil, A., K. Bertin, C. Meza, and V. Rivoirard, "Lasso-type Estimators for Semiparametric Nonlinear Mixed-Effects Models Estimation," Statistics and Computing, Vol. 24, No. 3, pp. $443-460$.

Bernanke, B., J. Boivin, and P. Eliasz, 2005, "Measuring the Effects of Monetary Policy: a Factor-Augmented Vector Autoregressive (FAVAR) Approach," Quarterly Journal of Economics, Vol. 120, No.1, pp. 387-422.

Board of Governors of the Federal Reserve System, 2014, "2015 Supervisory Scenarios for Annual Stress Tests Required under the Dodd-Frank Act Stress Testing Rules and the Capital Plan Rule," (Washington, D.C.).

Breuer, T., M. Jandacka, K. Rheinberger, and M. Summer, 1999, "How to Find Plausible, Severe, and Useful Stress Scenarios," International Journal of Central Banking, Vol. 5, No. 3, pp. 205-224.

Bookstaber, R., J. Cetina, G. Feldberg, M. Flood, and P. Glasserman, 2013, "Stress Tests to Promote Financial Stability: Assessing Progress and Looking to the Future," Office of Financial Research, Working Paper \#0010 (U.S. Department of the Treasury).

Borio, C., M. Drehmann, and K. Tsatsaronis, 2012, "Stress-Testing Macro Stress Testing: Does It Live Up to Expectations?” BIS Working Paper No. 369 (Basel: Bank for International Settlements).

Broadie, M., 1993, “Computing Efficient Frontiers Using Estimated Parameters,” Annals of Operations Research, Vol. 45, No. 1, pp. 21-58.

Brodie, J., I. Daubechies, C. De Mol, D. Giannone, and I. Loris, 2009, "Sparse and Stable Markowitz Porfolios," Proceedings of the National Academy of Sciences of the USA, Vol. 106, No. 30, pp. 12267-12272.

Bruder, B., J.-C. Richard, and T. Roncally, 2013, "Regularization of Portfolio Allocation," working paper, Lyxor Asset Management (Paris).

Chan-Lau, J.A., 2015, "Structural Market-Based Top-Down Stress Tests of the Banking System," Global Credit Review, Vol. 5, No. 1, pp. 1-14.

Chan-Lau, J.A., C. Chuang, J.-C. Duan, and W. Sun, 2015, "Systemic Risk in ForwardLooking Default Correlation Financial Networks: A Practical Approach," mimeo, Risk Management Institute, National University of Singapore. 
Chan-Lau, J.A., and L. Lin, 2015, “A Machine Learning Stress Testing Integrated Tool: Users Guide," mimeo.

Claeskens, G., and N.L.D. Hjort, 2008, Model Selection and Model Averaging (Cambridge University Press).

DeMiguel, V., A. Martin-Utrera, and J. Nogales, 2011, "Size Matters: Optimal Calibration of Shrinkage Estimators for Portfolio Selection," mimeo, London Business School and Universidad Carlos III de Madrid.

De Mol, C., D. Giannone, and L. Reichlin, 2008, "Forecasting a Large Number of Predictors: Is Bayesian Regression a Valid Alternative to Principal Components?" Journal of Econometrics, Vo. 145, pp. 318-328.

Demirer, M., F. Diebold, X. Liu, and K. Yilmaz, 2015, "Estimating Global Bank Network Connectedness," mimeo, MIT, University of Pennsylvania, and Koc University.

Duan, J.-C., and E. Van Laere, 2012, "A Public Good Approach to Credit Ratings - from Concept to Reality," Journal of Banking and Finance, Vol. 36, pp. 3239 - 3247.

Duan, J.-C., W. Miao, and T. Wang, 2014, "Stress Testing with a Bottom-Up Corporate Default Prediction Model," (Singapore: Risk Management Institute, National University of Singapore).

Duan, J.-C., J. Sun, and T. Wang, 2012, "Multiperiod Corporate Default Prediction - a Forward Intensity Approach,” Journal of Econometrics, Vol. 170, pp. 191 - 209.

European Systemic Risk Board, 2014, "EBA/SSM Stress Test: the Macroeconomic Adverse Scenario," 17 April (Frankfurt).

Fan, J., J. Lv, and L. Qi, 2011, "Sparse High-Dimensional Models in Economics," Annual Review of Economics, Vol. 3, pp. $291-317$.

Fan, J., J. Zhang, and K. Yu, 2012, "Vast Portfolio Selection with Gross-Exposure Constraints," Journal of the American Statistical Association, Vol. 107, No. 498, pp. 592-606.

Flood, M., and G. Korenko, 2013, "Systematic Scenario Selection,” Office for Financial Research, Working Paper \#0005 (U.S. Department of the Treasury).

Friedman, J., T. Hastie, and Tibshirani, 2010, "Regularization Paths for Generalized Linear Models via Coordinate Descent," Vol. 33, No. 1, pp. 1-22.

Gefang, D., 2014, "Bayesian Doubly Adaptive Elastic-Net Lasso for VAR Shrinkage," International Journal of Forecasting, Vol. 30, No. 1, pp. 1-11. 
Geweke, J., 1977, “The Dynamic Factor Analysis of Economic Time Series,” in D. J. Aigner and A. S. Goldberger, Latent Variables in Socio-Economic Models (Amsterdam: North Holland).

Glasserman, P., C. Kang, and W. Kang, 2014, "Stress Scenario by Empirical Likelihood," Quantitative Finance, Vol. 15, No. 1, pp. 25-41.

Goeman, J., R. Meijer, and Nimisha Chaturvedi, 2014, "L1 and L2 Penalized Regression Models," mimeo, available at cran.r-project.org.

Guan, Zhangran, Qian Luo, Gangxuan Wang, and Baoxin Wu, 2014, "Satellite Models in Stress Tests: Automatic Model Fitting," Credit Practicum Report, Risk Management Institute, National University of Singapore.

Gyorfi, L., G. Ottucsak, and H. Walk, 2012, Machine Learning for Financial Engineering, Advances in Computer Science and Engineering, Book 8 (Imperial College Press).

Hansen, B., 2013, “The Risk of James-Stein and Lasso Shrinkage,” forthcoming in Econometric Reviews.

Hastie, T., R. Tibshirani, and J. Friedman, 2008, The Elements of Statistical Learning: Data Mining, Inference, and Prediction (Springer Verlag).

Hastie, T., R. Tibshirani, and M. Wainwright, 2015, Statistical Learning with Sparsity: the Lasso and Generalizations, Monographs on Statistics and Applied Probability 143 (CRC Press).

Hoerl, A. E., 1962, “Application of Ridge Analysis to Regression Problems," Chemical Engineering Progress, Vol. 1958, pp. 54-59.

International Monetary Fund, 2012, Macrofinancial Stress Testing - Principles and Practices (Washington, D.C.).

Jagannathan, R., and T. Ma, 2003, "Risk Reduction in Large Portfolios: Why Imposing the Wrong Constraint Helps,” Journal of Finance, Vol. 58, No. 4, pp. 1651-1684.

Jakubik, P., and G. Sutton, "Thoughts on the Proper Design of Macro Stress Tests," BIS Papers No. 60, pp. 111-119 (Basel: Bank for International Settlements).

James, G., C. Paulson, and P. Rusmevichientong, 2013, "Penalized and Constrained Regression," mimeo, Marshall School of Business, University of Southern California.

James, G., D. Witten, T. Hastie, and R. Tibshirani, 2013, An Introduction to Statistical Learning with Applications in $R$ (Springer Verlag: New York). 
Jorion, P., 1992, "Portfolio Optimization in Practice," Financial Analysts Journal, Vol. 48, No. 1, pp. 68-74.

Kan, R., and G. Zhou, 2007, "Optimal Portfolio Choice with Parameter Uncertainty," Journal of Financial and Quantitative Analysis, Vol. 42, No.3, pp. 621-656.

Kapinos, P., and O.A. Mitnik, 2015, "A Top-Down Approach to Stress-Testing Banks," mimeo (Washington, D.C.: Federal Deposit Insurance Corporation).

Kock, A., 2012, "Consistent and Conservative Model Selection with Adaptive LASSO in Stationary and Nonstationary Autoregressions," forthcoming in Econmetric Theory.

Kock, A., and L. Callot, 2015, "Oracle Inequalities for High Dimensional Vector Autoregressions," Journal of Econometrics, Vol. 186, No. 2, pp. 325-344.

Li, J., and W. Chen, 2014, "Forecasting Macroeconomic Time Series: LASSO-based Approaches and their Forecast Combinations with Dynamic Factor Models," International Journal of Forecasting, Vol. 30, No. 4, pp. 996 - 1015.

Meinshausen, N., 2007, "Lasso with Relaxation," Computational Statistics and Data Analysis, Vol. 52, No. 1, pp. 374-393.

Meinshausen, N., and P. Buhlmann, 2006, "High Dimensional Graphs and Variable Selection with the Lasso," The Annals of Statistics, Vol. 34, No. 3, pp. 1436-1462.

Miller, A., 2002, Subset Selection in Regression, $2^{\text {nd }}$ edition ( Chapman Hall).

Mohri, M., A. Rostamizadeh, and A. Talwalkar, 2012, Foundations of Machine Learning (MIT Press).

National University of Singapore, Risk Management Institute, CRI database. Available at http://rmicri.org (Accessed April 2014).

Orphanides, A., 2015, "Stress Tests as a Policy Tool: the European Experience during the Crisis," mimeo (Cambridge, MA: Sloan School of Management, MIT).

Perdeiy, V., 2009, "Bankruptcy Prediction Revisited: Non-traditional Ratios and Lasso Selection," mimeo (Deutsche Bank Group).

Rosch D., and H. Scheule, editors, 2008, Stress Testing for Financial Institutions (London: Risk Books).

Scherer, B., 2010, Portfolio Construction and Risk Budgeting, $4^{\text {th }}$ edition (London: Risk Books). 
Siddique, A., and I. Hasan, 2013, Stress Testing: Approaches, Methods, and Applications (London: Risk Books).

Song, S., and P. Bickel, 2011, "Large Vector Auto Regressions," mimeo (University of California, Berkeley).

Stock, J., and M. Watson, 2002, "Forecasting Using Principal Components from a Large Number of Predictors," Journal of the American Statistical Association, Vol. 97, No. 460, pp. $1167-1179$.

Tateishi, S., H. Matsui, and S. Konishi, 2010, "Nonlinear Regression Modeling via the Lasso-Type Regularization," Journal of Statistical Planning and Inference, Vol. 140, No. 5, pp. $1125-1134$.

Tibshirani, R., 1996, "Regression Shrinkage and Selection via the Lasso," Journal of the Royal Statistical Society, Series B (Methodological), Vol. 58, No. 1, pp. 267-288.

Yuen, K., 2013, "Determining the Severity of Macroeconomic Stress Scenarios," Supervisory Staff Report, December (Washington, D.C.: Board of Governors of the Federal Reserve).

Zandi, M., 2013, "Designing Macroeconomic Scenarios for Stress Testing," (New York: Moody's Analytics).

Zhang, J., editor, 2013, CCAR and Beyond - Capital Assessment, Stress Testing and Applications (London: Risk Books). 